\title{
A Simple Test Method for Large Deformation Bending of Thin High Strain Composite Flexures
}

\author{
Juan M. Fernandez* \\ NASA Langley Research Center, Hampton, VA 23681, USA \\ and \\ Thomas W. Murphey ${ }^{\dagger}$ \\ Opterus Research \& Development Inc., Fort Collins, CO 80526, USA
}

\begin{abstract}
A simple test method for large deformation bending of thin composite laminates is investigated using image processing and full-field strain measurements. The assumptions and kinematic equations that represent the test are used to calculate numerically the laminate bending stiffness and strength as well as the curvature and strains at failure. In order to validate the test methodology, a comparison is performed between analytical model predictions and empirical data in terms of computed surface strains versus digital image correlation data and calculated rotation angles of the fixture arms throughout the test versus measured ones. The new test method is then used to calculate the bending stiffness in the $D_{11}$ and $D_{22}$ directions as well as failure strains for various thin-ply laminates of interest. These parameters are ultimately compared with predicted values using micromechanics and classical lamination theory analysis. In general, bending stiffness and strain test results and predictions for 0 degree orientation coupons have a maximum difference of $10 \%$ and $35 \%$.
\end{abstract}

\section{Introduction}

Initial work in the field of high strain composites (HSC) revealed that thin-shell composite elements subjected to large bending deformations can attain significantly higher strains to failure than previously anticipated, considering linear material model assumptions and constitutive material manufacturer's tensile and compression coupon test data $^{1,2}$. This effect has been investigated in flat coupons of woven-ply carbon fiber reinforced plastic (CFRP) materials subjected to pure moments ${ }^{3}$, as well as in woven cylindrical shell structures, e.g. tape-springs ${ }^{4,5}$ and tubular hinges ${ }^{6}$. To exploit this benefit, new flexural elements rely on thin composite laminates to sustain bending strains of over $1.5 \%$ and for which the nonlinear behavior of the reinforcing fibers is significant ${ }^{7}$. Accurate prediction of the strain and stress states of these flexural elements and their failure modes are necessary to develope HSC structures with improved packaging efficiency and deployed structural performance. In addition, during bending the HSC material exhibits fiber tensile stiffening and compression softening, with a net effect that results in a gradual reduction in bending stiffness with the increase in strain ${ }^{8,9}$. These amplified strains seen in thin flexures were attributed to tension mechanics causing an increase in local shear stiffness that stabilizes the compressive fibers by the adjacent tensile fibers ${ }^{9}$. As a result, this prevents a compressive micro-buckling failure mode commonly observed in thicker composite samples ${ }^{4,8,9}$. Since the majority of these HSC laminate structures rely on the stored strain energy of the packaged configuration to attain a final deployed state, it is important to accurately measure the laminate flexural rigidity over the operational strain regime of the material, and from this, assess the behavior of the HSC structure during stowage and deployment.

The traditional flexural testing methods for beams, i.e. three-point and four-point bending tests ${ }^{10-11}$, were not suitable for thin composite flexures as the elastic deformations, prior to failure of these thin elements, result in large configuration changes that cannot be accommodated by these test configurations. Thus, one of the challenges for analyzing the bending behavior of thin-ply composite structures is developing new testing methods that allow large deformations on the specimens under realistic loading and boundary conditions to measure nonlinearities in the

\footnotetext{
${ }^{*}$ Research Aerospace Engineer, Structural Dynamics Branch, NASA LaRC, 4 West Taylor Street, Mail Stop 230. AIAA Member.

${ }^{\dagger}$ President. Opterus Research \& Development, Inc., 4221 Rolling Gate Rd, Fort Collins, CO. AIAA Associate Fellow. 1

American Institute of Aeronautics and Astronautics
} 
moment-curvature relationship at large strains. Three main tests have been developed or adapted over the last decade for understanding the behavior of HSC flexures, with each having their own challenges and limitations.

In the simple vertical test ${ }^{3}$, the moment-curvature relationship was obtained from the post-buckling behavior of the sample under compressive loads. As shown in Fig. 1 (a), the test uses tape that act as hinges allowing rotation of the coupon into a U-shape under direct compression applied by a uniaxial testing machine. For ease of testing, the ends of the coupons are clamped between thin metal plates ${ }^{12}$, with the outer plate taped to the fitting of the load frame. As the bending stiffness of the tape was much lower than the specimen, the tape was treated as a perfect hinge ${ }^{12}$. However, this vertical test method is prone to gravity-induced horizontal lateral loads that tend to produce coupon/tape shear distortion at large angles of rotation or induced curvatures. This shear component results in unbalanced test configurations of the clamping plates (top and bottom) that experience different rotation angles to reach moment equilibrium in the system. This effect is more pronounced on soft coupons that require relatively larger/heavier clamping plates, making this test method mainly applicable to testing thin laminates.

In the platen test, $180 \mathrm{deg}$ bent U-shape coupons were placed between two flat compression platens, as shown in Fig. 1 (b). The platens were then monotonically driven closed inducing progressively tighter curvatures on the specimens. This platen test ${ }^{5}$ was used to fold cylindrical shells that were initially flattened between clamping plates, inducing the expected biaxial bending loads in tape-spring structures. In Ref. 7 and 8, flat unidirectional reinforced coupons were platen-tested and demonstrated that the curve, formed by the U-shaped folded coupon, follows the geometry of an elastica curve (similar to an ellipse) instead of a circle. This means that pure moments were not acting at the point of transition between the flat and curved sections, and that transverse loads induced compressive strains at the coupon midsection. Consequently, the midsection attains the highest curvature under a stress concentration, where failure is expected to occur. Although this test can be used for determining an upper limit on maximum coupon curvature, or for computing strains and stresses at failure, it does not represent well the pure bending states experienced in HSC structures.

To overcome the aforementioned limitations, a new large deformation four-point bending (LD-FPB) test was developed $^{13}$. The complex LD-FPB test fixture is shown in Fig. 1 (c), which has several precision-machined and polished components. The fixture is a variation of the four-point bending test that subjects the specimen to a pure bending stress state. The both ends of the coupon are clamped to each cart. As the load head is driven downward, the carts are forced to rotate flexing the sample. Unfortunately, in some occasions, clamping the coupons edges results in stress concentrations in these areas, leading to failure at the grips. Flexing the coupon around the edge of the steel grip can induce premature failure at the point of load transition rather than in the gage section. A recent effort to measure the flexural rigidity and failure conditions of thin unidirectional composite flexures resulted in a three-step characterization process that only used the LD-FPB test to assess bending stiffness, including the nonlinear effects of the reinforcing fiber in the composite test specimen, and not failure properties (curvature, stresses and strains) of the flexures ${ }^{9,14}$. For the latter, the more common platen tests still needs to be performed. The LD-FPB test was also recently used to assess the bending stiffnesses of thin carbon and glass fiber composite tape-spring designs ${ }^{15}$.

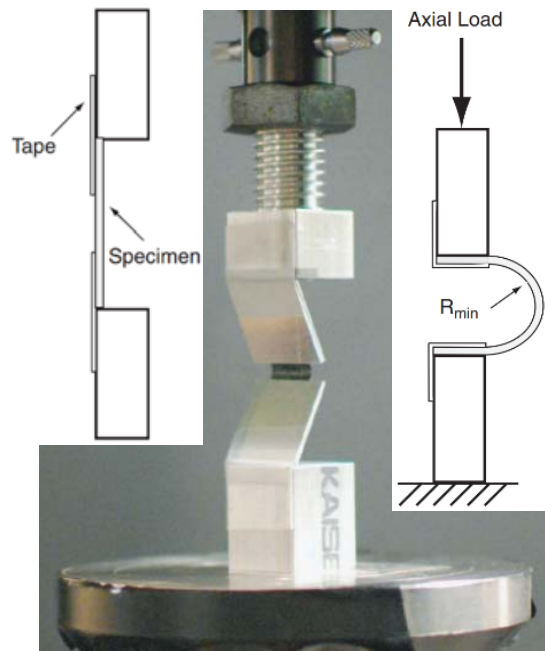

(a)

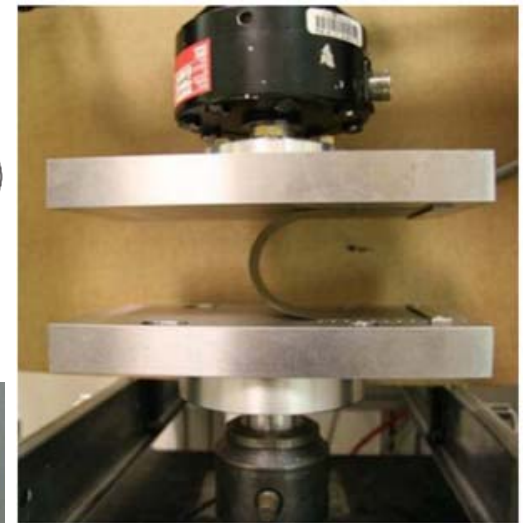

(b)

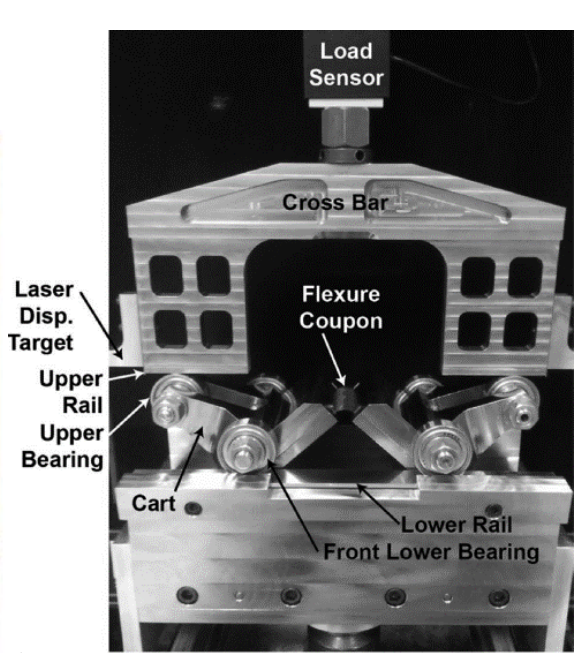

(c)

Fig. 1. Previously developed large deformation bending test methods for thin composite flexures: (a) simple vertical test method $^{1,10}$, (b) platen test ${ }^{6}$, and (c) large deformation four-point bending (LD-FPB) test ${ }^{7}$. All pictures shown were taken at a representative middle stage during the test. 
The aim of this research effort was to conduct further investigations into an alternative test method, named the Column Bending Test (CBT) because it resembles a column subjected to axial compression, which combines the best features of the platen test and the large deformation four point bending tests. The ultimate objective of this effort was to evaluate this technique for determining the flexural rigidity and failure parameters of thin laminate flexures in a single simple test by measuring the bending moment and curvature of the coupons to failure under pure bending stress conditions. The slopes of the moment-vs-curvature curves provide the laminate bending stiffness matrix constants $(D$ values of the common $A B D$ matrix). The evaluation of these curves also determine material nonlinearities and progressive failure behavior of the material coupons. Accurate measurements of test parameters and coupon data was used to assess and validate the CBT method proposed. The test method was used to characterize several thin-ply materials and laminates of interest to NASA for current small satellite structural applications ${ }^{16,17}$ that use new HSC booms ${ }^{18,19}$, and could form the basis for a widely accepted HSC material testing standard.

\section{Column Bending Test}

The bending test method employed here was first developed for the large deformation flexural test of composite tubes at Opterus R\&D and subsequently adapted and improved for thin composite flexures at Opterus R\&D. Under a following effort, NASA Langley Research Center (LaRC) has fabricated additional lightweight CBT fixtures and evaluated the bending method for ultrathin laminates of interest. There were initial concerns with the uncertainty and risk associated with a new test method, due to the non-existent basis and inexperience employing this test method, with the potential for erroneous results. While the test has been used by industry, the work presented herein was one of the first openly published results of the flexural test method for the bending characterization of thin laminates for space applications. A similar CBT fixture was recently used to measure time dependency on failure curvature in a HSC laminate during a parallel effor $\mathrm{t}^{20}$. While the aforementioned publication focused on the test results gathered with a CBT fixture, this research presents the test method and the investigation of its nonlinear mechanics and validity of assumptions made.

The platen test generates a small localized region of high curvature, well away from coupon boundary conditions. Due to statistical considerations and the relatively small volume of material subjected to high stresses, the platen test results in uncharacteristically high failure strains. The moment throughout the coupon is highly non-uniform, requiring complex structural analyses to interpret test results. In contrast, the large deformation four point bending test generates a perfectly uniform stress state that transitions from flat to fully curved at the coupon grips. While the uniform stress state allows bending curvatures and moments to be determined quite accurately, the abrupt transition from flat to curved causes premature failure at the test grips. These limitations led to the approach used ${ }^{14}$ to characterize HSC laminates that employ the platen test for strength, and the LD-FPB test for stiffness.

CBT hybridizes the platen and LD-FPB tests to generate a maximum coupon stress state at the coupon center (as in the platen test), decreasing to $80-90 \%$ of the maximum at the coupon grips. In contrast, the stress in the platen test reduces to zero where the coupon touches the platens. In the CBT, the stress state is mostly uniform, allowing a simple kinematic analysis to estimate moments and curvatures. Since the curvature is reduced at the grips, failure is likely to occur in the coupon center. Also, because a larger volume of material is subjected to high stress, the results are more precise.

The CBT fixture effectively attaches rigid arms to each end of a coupon, as shown in Fig. 2 (a). Although the CBT presented here is vertically setup common to uniaxial test machines, horizontal test configurations are acceptable using dedicated displacement-driven load frames. The arms are pinned at their ends with the pin axes offset from the coupon neutral axis. This creates a two force member such that an applied compression force, bringing the pins close together, causes a bending moment in the coupon. As in the platen test, the coupon axial stress is negligible compared to the bending stresses generated in the coupon. As the load pins are brought closer, the coupon behaves like a buckled column, and loads initially decrease. This is related to the nonlinear kinematics of how the load moment arm initially increases significantly even for very small pin displacements. As the test progresses, the opposite is true and large pin displacements causes relatively small changes in the moment arm length. To reduce friction, the pinned fixture arm ends rotate freely on bearings on a U-shape clevis affixed to the load frame. The other ends clamp the coupon with a rigid grip plate screwed into the arm, effectively sandwiching the coupon.

An approximation to the CBT kinematics is readily derived assumpting constant curvature of the specimen throughout the test. In reality, the moment varies in the coupon from a minimum at the coupon grips to a maximum at the coupon center. This moment variation leads to curvature variations. Inaccuracies from this assumption are still being explored and in cases with especially short arms, a large deformation structural analysis will likely be required to achieve accurate results. Since stresses are highest away from the grips in the central region of the specimen, grip induced failures are minimized on samples that have significant gage lengths. 
Figure 2 (a) shows a CBT fixture made from polylactic acid (PLA) using additive manufacturing. In order to keep the mass of the fixture low to limit the amount of error induced by gravity, a fill rate of $25 \%$ for the arms and $75 \%$ for the grips was used in the build. Nylon fasteners used for clamping the coupons were also selected to minimize the mass of the system. The physical fixture is idealized in Fig. (b) in order to derive the kinematic equations relating the load and displacement data to the bending stiffness and curvature of the laminate.

In Fig. 2 (b), $s$ is defined as the free length of the coupon between the clamps or gage length, $l$ is the effective length of the rigid fixture arm, $\theta$ is the initial angle of the fixture arm, $\phi$ is the change in fixture arm angle due to deflection, $\delta$ is the linear vertical displacement of the fixture, $P$ is the load applied to the fixture, $r$ is the effective moment arm length, and $R$ is the radius of curvature of the bent coupon.

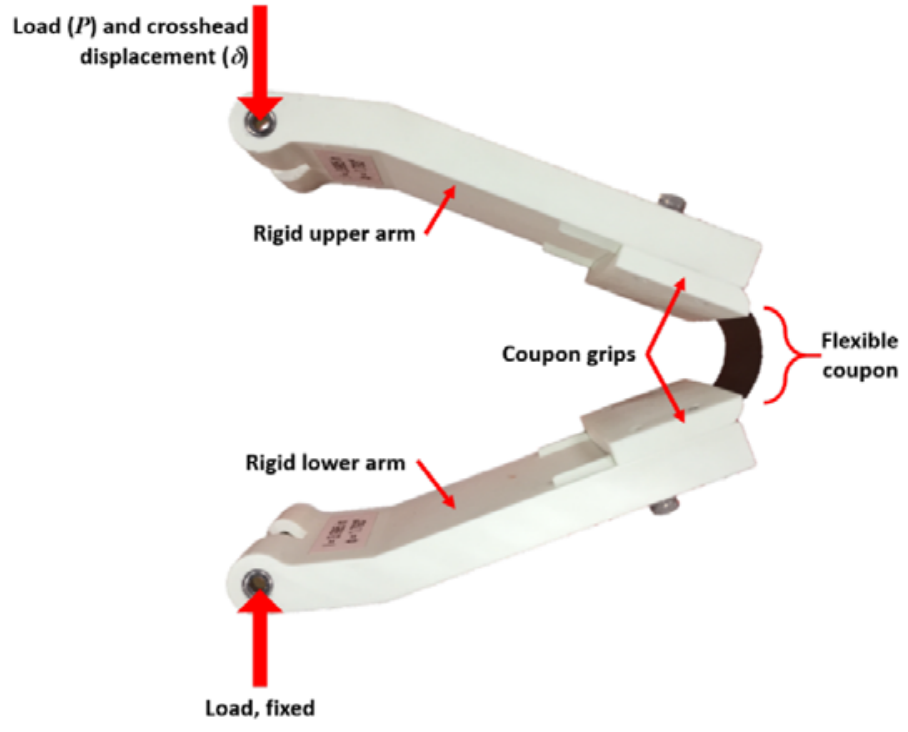

(a)

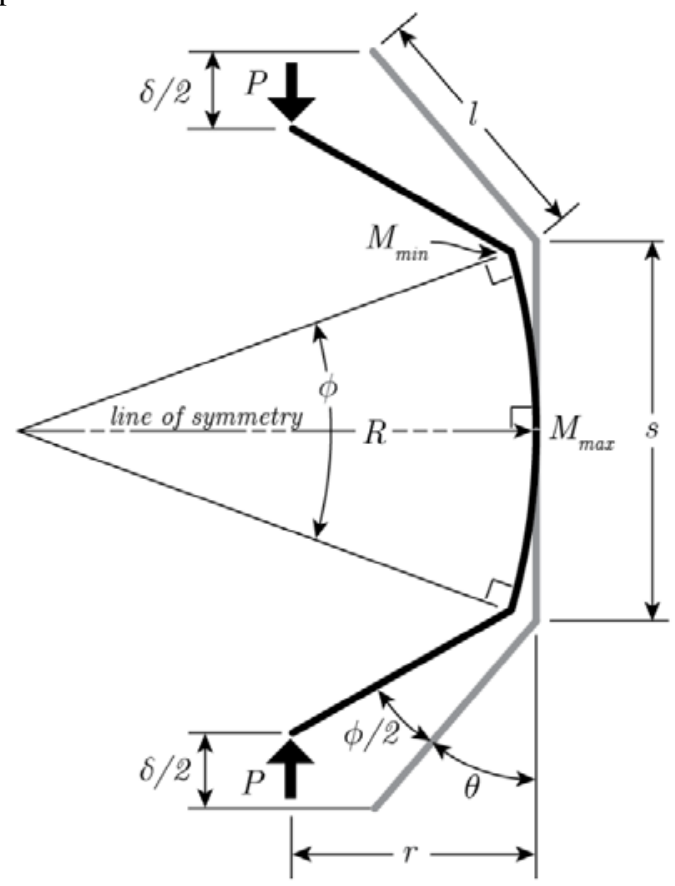

(b)

Fig. 2 (a) Lightweight plastic CBT fixture with a thin flexure clamped midway through a bending test; (b) Idealization of the CBT showing all the test parameters involved.

Since the maximum curvature occurs at the center of the sample and the variation between the minimum and maximum moments is relatively small, a constant curvature of the specimen is assumed. Under this assumption, the kinematic equations of motion are apparent and the relationship between the displacements of the fixture ends, $\delta$, to the total change in both fixture arm rotation angles, $\phi$, is:

$$
\frac{\delta}{s}=1-\frac{2}{\phi} \sin \frac{\phi}{2}+2 \frac{l}{2}\left(\cos \theta-\cos \left(\theta+\frac{\phi}{2}\right)\right) \text {. }
$$

Is it worth noting that Eq. 1 is transcendental and $\phi$ cannot be solved for directly without employing numerical methodology. This was implemented in a Matlab script here.

Using the arc length formula, the curvature of the sample, $\kappa=1 / R$, can then be determined by:

$$
\kappa=\frac{\phi}{S} \text {. }
$$

The effective moment arm length, $r$, is calculated using trigonometry based on the geometry of the fixture, the rigid arm angle computed, $\phi$, and the applied load, $P$, by:

$$
\frac{r}{s}=\frac{1}{\phi}\left(1-\cos \left(\theta+\frac{\phi}{2}\right)\right)+\frac{l}{s} \sin \left(\theta+\frac{\phi}{2}\right) .
$$


With the curvature of the sample and assuming the material is linear, it is then possible to find the surface strain of the laminate, $\varepsilon$, using the thickness of the coupon, $t$, by:

$$
\varepsilon=\frac{\kappa \mathrm{t}}{2}
$$

The maximum moment acting on the sample can be determined with the computed moment arm length, $r$, and the measured load, $P$, by:

$$
\mathrm{M}_{\max }=\operatorname{Pr}
$$

For reference, the minimum moments acting on the coupon near each grip is:

$$
M_{\min }=P l \sin \left(\theta+\frac{\phi}{2}\right) \text {. }
$$

With the computed maximum moment and curvature data it is possible to obtain a plot of moment-vs-curvature throughout the deflection of the coupon. The slop of this graph is the material bending stiffness, $D$, that can be determined through the following relation:

$$
D=\frac{\partial M_{\max }}{\partial \kappa} .
$$

From evaluating these equations, the only independent variables that require measurement during the test are the linear displacement of the fixture arms, $\delta$, and the load acting on the fixture from bending the coupon, $P$. During the test, the former is controlled by the load frame, while the latter is measured by a load cell in line with the CBT fixture.

\section{A. Gravity Effects on Weight-Unbalanced Test Configurations}

The simple kinematic equations of motion aforementioned are only applicable to cases where gravity-induced loading is not present, which is true in weight-balanced or horizontal test configurations. Note that the unbalanced test fixture of Fig. 2 (a), as was the case of the vertical test shown in Fig. 1 (a), the fixture weight creates an additional bending moment on the coupon, which increases as the test progresses and the moment arm grows.

Therefore, gravity causes two types of errors in CBT results. First, the weight of each test fixture arm, $w$, decreases the reaction force at the upper load pin and increases the reaction force at the lower pin. Due to the compliance of the coupon and symmetry of the system, it is reasonable to assume equal weight sharing. Here, the upper pin fully carries the weight of the upper arm, and the lower pin fully carries the weight of the lower arm. This error is simple to correct. If load is measured (e.g. with a load cell) from the upper pin, the weight of a single fixture arm should be added to the measured load. Similarly, if load is measured at the lower pin, the weight of a single fixture arm should be subtracted from the measured load.

Second, gravity causes a shearing distortion in the coupon. This misalignment is not readily correctable, but can be understood and assessed from a static equilibrium analysis of the fixture and coupon throughout testing. The transverse force on each loading pin, $F_{s}$, is found my summing moments on the system free body diagram as shown in Fig. 3,

$$
F_{S}=2 w \frac{x}{L} \sin \left(\theta+\frac{\phi}{2}\right)
$$

where $L$ is the distance from upper to lower pins, and $x$ is the distance from the pin to the arm center of mass.

This force is negligible at the beginning of a test when the pin-to-pin separation, $L$, is largest and the sine term is smallest. The force is largest at the end of a test when the arms are near horizontal and $L$ is smallest. In practice, tests should stop when the arms are horizontal. Beyond this point, $L$ becomes very small and the side force becomes a significant shearing force on the coupon. As a result, the test fixture sags creating a higher curvature towards the lower arm, and a lower curvature towards the upper arm. In addition to keeping the test fixture mass low and avoiding very small $L, x / L$ should be minimized by keeping the test fixture center of mass close to the loading pin.

A static analysis of a test fixture arm shows the moment required to keep an arm in equilibrium is,

$$
M_{c \pm}=\left\{P l \mp w x\left[1-2 \frac{l}{L} \cos \left(\theta+\frac{\phi}{2}\right)\right]\right\} \sin \left(\theta+\frac{\phi}{2}\right) .
$$

American Institute of Aeronautics and Astronautics 


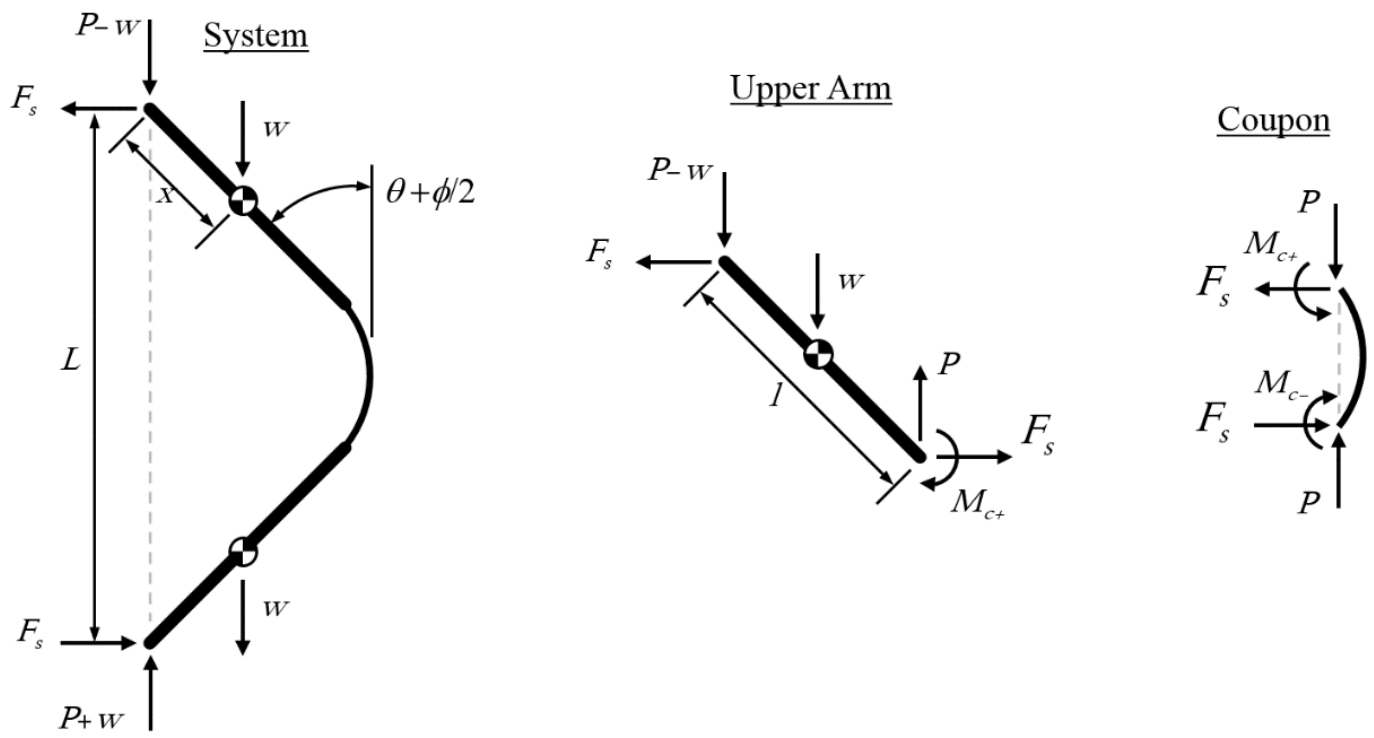

Fig. 3. CBT system, upper arm and coupon free body diagrams with gravity forces.

The second term in Eq. 9 is the gravity load induced moment. The moment in the upper fixture arm, $M_{c+}$, is decreased (-) by gravity while it is increased (+) in the lower arm, $M_{c .-}$. The arms effectively rotate downward by similar angles until a new equilibrium is achieved. This effect is exemplified in Fig. 4 for the first heavier metal CBT fixture produced (total mass of $142 \mathrm{~g}$ ), for a lighter metal version $(88 \mathrm{~g})$ and for the lightest plastic one (42 g). Note that the three examples presented are extreme cases, and this shear-induced moment that drives the arms downwards was not as severe during the tests. This is particularly true for the lightest fixture.

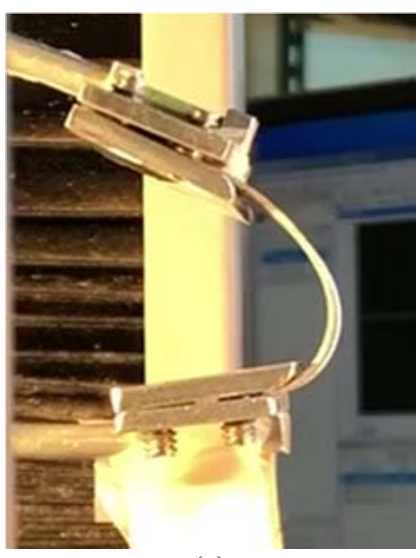

(a)

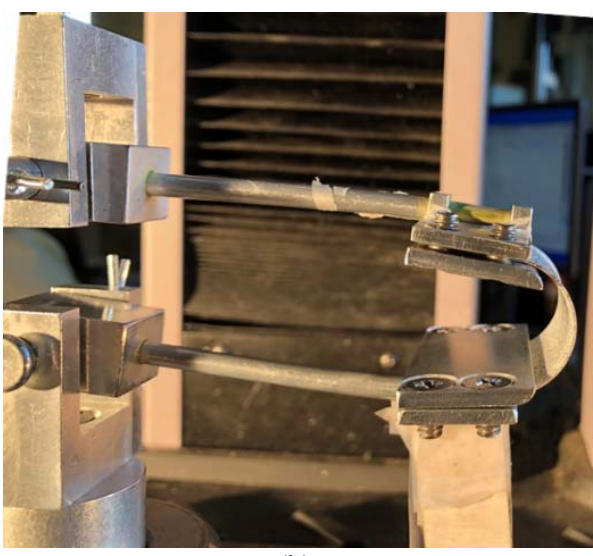

(b)

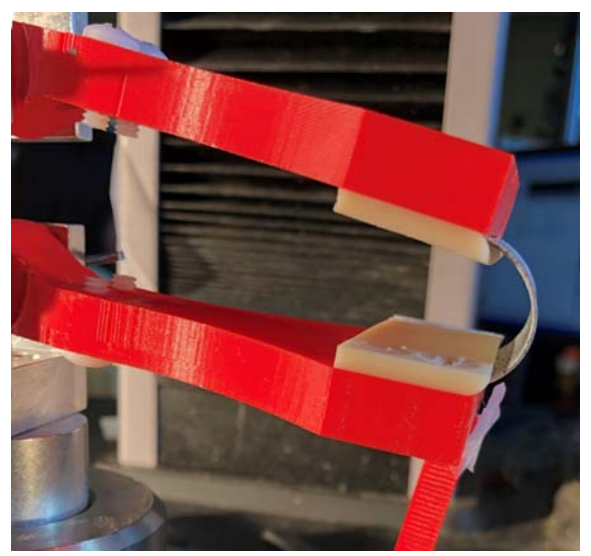

(c)

Fig. 4. Gravity-induced moments on three weight-unbalanced CBT fixtures causing the arms to sag at large rotation angles: (a) heavy metal fixture; (b) light metal fixture; and (c) lightest plastic fixture. These images represent worst cases.

From evaluating Eq. 8 and 9, it is clear that there are three fixture and test related parameters that affect the gravityinduced shear force, $F_{s}$, and resultant moments, $M_{c}$, on the coupon. Neglecting the mass of the coupon itself (a few percent of the fixture arm), and considering a linearly distributed weight for the fixture arms, these are: the mass of the fixture arm, $w$, the fixture arm length, $l$, and the coupon gage length, $s$. The last two parameters are related to $L$ and $x$ by:

$$
L=2 l+s=4 x+s .
$$

Parametric analyses for the three parameters were run to evaluate their impact on the gravity-induced moment on the CBT fixture. Figure 5 shows the gravity-induced shear force and moment nondimensionalized by the maximum values obtained as each fixture arm goes through a full 90 deg rotation $(\phi=180 \mathrm{deg}$ in total) for three different fixture arm masses. The masses were representative of the fixture designs shown in Fig. 4. For these cases, a coupon gage length of $s=25.4 \mathrm{~mm}$ and arm length of $l=94 \mathrm{~mm}$ was assumed. Both the shear force and moment grow as the 
rotation angle increases with a rapid increase in the last 10 deg of rotation. Lighter fixture designs induce smaller forces and moments with a direct proportionality of the fixture mass, i.e. the ratio of two fixture masses is equal to the offset between the two respective graphs, as expected from evaluating Eq. 8 and 9. Note that the graphs start at an arm rotation angle of $5 \mathrm{deg}$, which is normally the minimum initial angle, $\theta$, necessary to pre-buckle the coupon prior to starting the test.
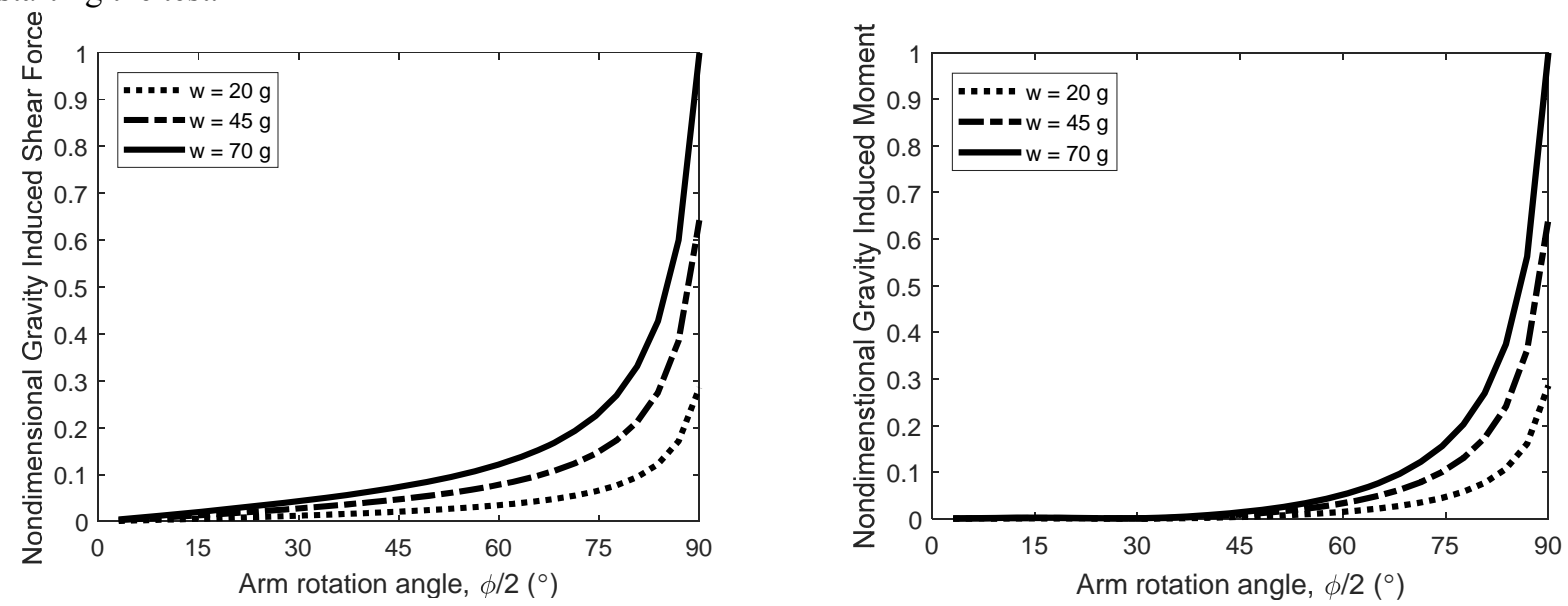

Fig. 5. Nondimensionalized gravity-induced shear force (left) and moment (right) as each fixture arm goes through a full 90 deg rotation for three different fixture arm masses, $w$.

Plots similar to the above can be generated by varying the other two related parameters. Figure 6 presents the nondimensionalized gravity-induced moment as each fixture arm goes through a full 90 deg rotation (180 deg in total) for three different fixture length arms (left) and coupon gage lengths (right). Once more the initial rotation angle adopted is $5 \mathrm{deg}$. In Fig. 6 (left), a fixture arm mass of $w=21 \mathrm{~g}$, coupon gage length of $s=25.4 \mathrm{~mm}$ and a fixture design where $l=2 x$ was assumed. Relatively long fixture arm designs were initially fabricated for evaluation of the new test approach as it was easier to track their motion (side view) while clearing the load frame columns for longer arm designs (see Fig. 4 (a)). As expected, the induced moment increases with the length of the fixture arm. However, shorter fixtures are preferred that prevent the arms from sagging or collapsing towards the end of the test. Note, that the design with a $30 \mathrm{~mm}$ fixture arm length would only induce a moment about $10 \%$ that of the $90 \mathrm{~mm}$ design.

In Fig. 6 (right), a fixture arm mass of $w=21 \mathrm{~g}$ and a fixture arm length of $l=2 x=94 \mathrm{~mm}$ was assumed, similiar to the lightweight plastic fixture shown in Fig. 4 (c). In this case, increasing the coupon gage length actually reduces the gravity induced moment. As evidenced from the figure, a coupon with a gage length of $38.1 \mathrm{~mm}$ would experience about $30 \%$ of the unbalancing moment of a coupon with a gage length of $12.7 \mathrm{~mm}$. This could be counterintuitive, but a closer look at Eq. 9 shows that, for this particular case where $L$ depends solely on $s$ ( $x$ is constant), the term on the right diminishes as $s$, and thus $L$, grows. Eq. 8 also reflects the same inverse proportionality between $s$ and $F_{s}$. This means that thinner coupons needing smaller gage lengths to fail during a bending test, are more prone to gravity loading effects than thicker coupons.
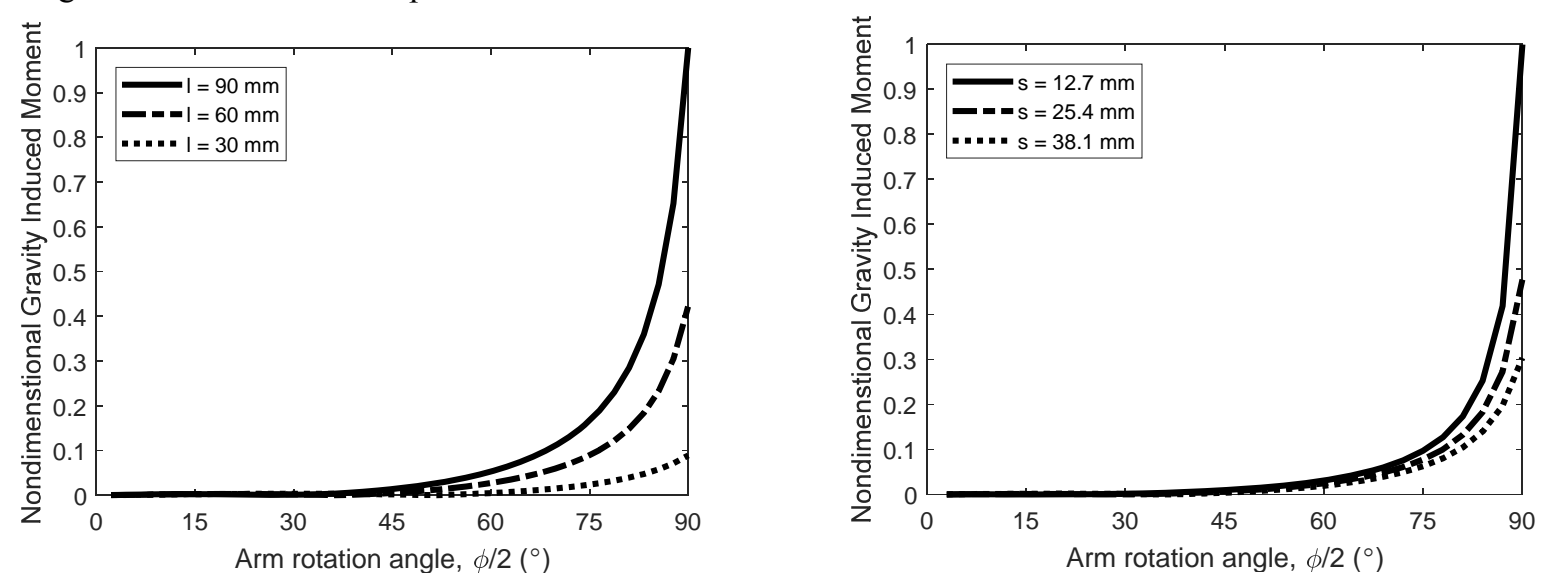

Fig. 6. Nondimensionalized gravity-induced moment as each fixture arm goes through a full 90 deg rotation for three different: fixture arm lengths, l, (left), and coupon gage lengths, s, (right). 


\section{B. Counterweight-Balanced Test Fixture}

After investigating and experiencing the detrimental effect of gravity on ultra thin CBT coupons, with the intent to representatively test ever-thinner laminate designs that require smaller gage lengths, $s$, a new CBT fixture design that is completely weight-balanced has been recently produced by Opterus R\&D. This design, named the counterweight balanced (CWB) CBT fixture, is double symmetrical about the loading pin axis. Hence, the fixture arm center of mass coincides with the load application point at the pin, and thus $x=0$. This translates to both the gravity induced shear force and moment to be zero (see Eq. 8 and 9), freeing the fixture from gravity loading effects by design. Note that for $x=0$, the moment to keep equilibrium in the CBT system, $M_{c}$, from Eq. 9 is the same at both coupon ends $\left(M_{c^{+}}=M_{c-}\right)$, and equates to the minimum moment, $M_{\min }$, from Eq. 6 .

Figure 7 shows the CWB CBT fixture. To minimize any possible weight-unbalanced effects, the fixture arm length is now only $s=25.4 \mathrm{~mm}$, and each fixture arm mass including the clamping plate is $w=23 \mathrm{~g}$. It can be seen that the weight of the fixture arms does not induce any sagging on the fixture as the test progresses. This allows the application of a balanced pure bending moment on the coupon as the fixture is put into compression. Note that a piece of paper with a random speckled patterns was taped to one side of the upper fixture arm to track its rotation throughout the test. A similar target was also attached to the lower fixture arm during other tests, demonstrating that the difference in rotation angle of each arm was within 4 deg throughout the test, even for very thin coupons $(<0.2 \mathrm{~mm})$, as shown in Fig. 8. This CWB CBT fixture is preferred as a better design for the vertical CBT.

Lateral alignment of the two fixture arms inside the U-shape clevis is carried out with a set of precision blocks that guarantee all elements are squared. Additional precision blocks are also used at both sides of the coupon to guarantee a constant gage length, and that the coupon edges are aligned with the vertical axis. This prevents any unwanted twist (off-axis loads) induced on the coupon during bending.

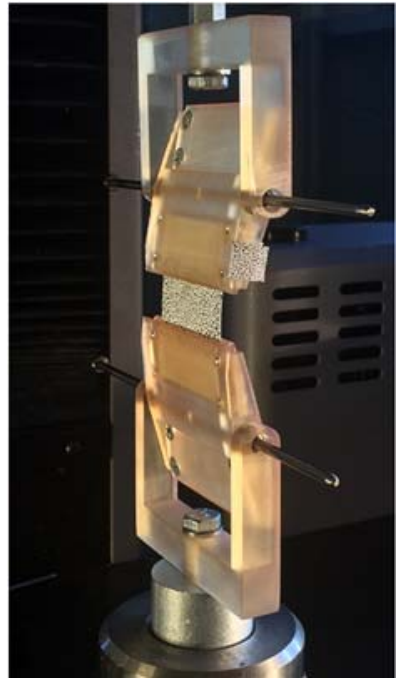

(a)

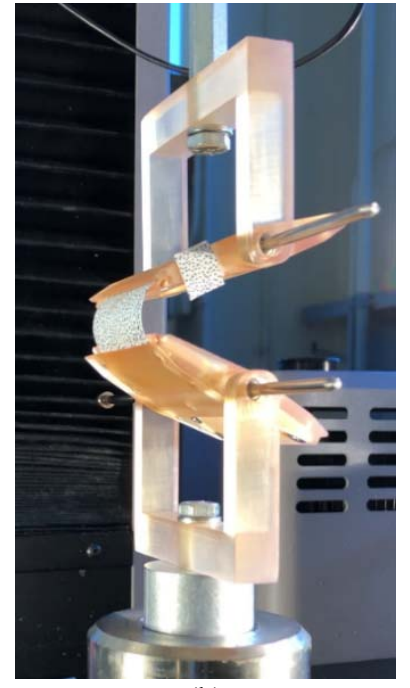

(b)

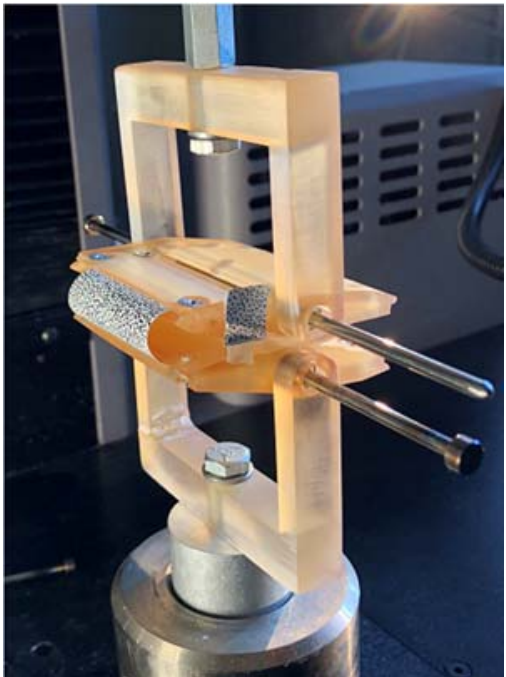

(c)

Fig. 7. Counter-weight balanced (CWB) CBT fixture at various stages of rotation during a test with a very thin 0.12mm-thick CFRP unidirectional coupon: (a) start $\left(\theta=5^{\circ}, \phi / 2=0^{\circ}\right)$, (b) halfway $\left(\phi / 2=40^{\circ}\right)$, and (c) end $\left(\phi / 2=80^{\circ}\right)$.

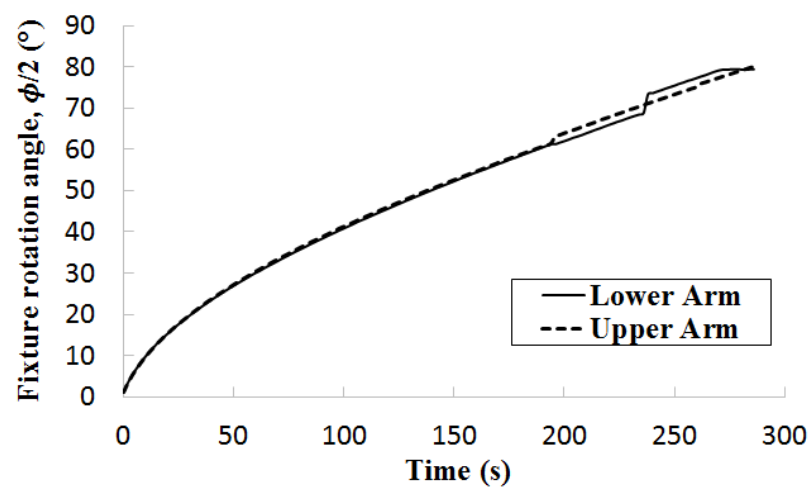

Fig. 8. Measured angle of rotation of the lower and upper counter-weight balanced fixture arms, $\phi / 2$, during a CBT. 


\section{Materials}

\section{A. Thin-Ply Composite Materials}

Thin-ply composite prepreg materials typically have cured ply thicknesses (CPT) below $65 \mu \mathrm{m}$ for unidirectional (UD) products and double that for textile fabrics. By comparison, a standard-ply-thickness UD material would have a CPT of approximately $125-150 \mu \mathrm{m}$. Commercially-available prepregs and dry fabrics are now available with ply thicknesses as thin as $15 \mu \mathrm{m}$ for UD materials and $50 \mu \mathrm{m}$ for weaved fabrics, in different quality levels. Thin-ply composites hold potential for reducing structural mass while increasing performance when compared to standard-plythickness laminates in terms of: resistance to micro-cracking, resistance to delamination, improved damage tolerance, improved aging and fatigue resistance, reduced minimum-gage thickness, and increased scalability. The composite materials investigated in this paper belong to the group of thin-ply materials.

For rigid composite structures, the availability of thin-ply composites materials broadens the design space, as more laminates with optimized fiber orientations are possible for the same overall laminate thickness and structural mass. For other HSC structural concepts, like foldable/rollable deployable composite structures, extremely thin plies are normally required due to the stringent stowed volume requirements, especially for small satellite applications ${ }^{16,18}$. However, the use of thin-ply composites technology has not been fully explored and exploited by the aerospace structures community. Common failure modes of composite structures subjected to high strains are resin microcracking and ply delamination that severely limit the full utilization of the fiber strength. Micro-cracking normally begins at strains of about $0.5 \%{ }^{21}$, well below the intended operational strain of HSC structures. Hence, if this failure mode can be suppressed through laminate design, composite structures could carry loads up to the failure strain limits of most modern intermediate modulus (IM) carbon fibers, which is about 2-2.2\% in tension and greater in compression for flexural loading. Thus, a secondary goal of this research effort was to evaluate state-of-the-art thin-ply materials and laminate designs of interest to HSC structures using the CBT approach, which allows studying failure modes experienced in thin HSC laminates.

The main disadvantages of using thin-ply materials are: their difficulty to acquire (high cost, long lead times and low availability, particularly on high modulus fibers that are more difficult to spread), lower quality (some degree of fiber twisting, misalignment and damage, thickness non-uniformity and gaps in the material), difficulty in obtaining rolls more than 25-50 $\mathrm{mm}$ wide without joining them (affects fiber misalignment), and the current lack of aerospace qualification processes. The lowest weight forms are also primarily developmental, and are typically fabricated on a best-effort basis with reduced batch to batch consistency.

Many thin-ply materials from various vendors have been sourced in the search of consistent high quality products. Most of the materials purchased are spread-tow fabrics manufactured from large tow (12-24K) unidirectional fiber bundles that go through a cumbersome and complex spreading process to reduce their thickness by up to six fold. Table 1 shows some of the thin-ply materials studied at NASA LaRC as part of this investigation. For brevity, a subset of materials under evaluation will be presented. The carbon fiber materials listed below are some of the lightest, good quality, intermediate modulus (IM) and high modulus (HM) products available worldwide to date. These preforme were impregnated in-house with a PMT-F7 toughened epoxy resin film with space heritage from Patz Materials and Technologies. Note that the fiber volume fractions (FVF) are somewhat low, particularly for the HS40/PMT-F7 material. This is because the areal weight (AW) of the PMT-F7 resin film used $\left(36.7 \mathrm{~g} / \mathrm{m}^{2}\right)$ was sized for the several thicker plain weave materials that were investigated (FAW: $60-80 \mathrm{~g} / \mathrm{m}^{2}$ ). A single layer of resin film was used to impregnate two HS40 plies, resulting in an approximate 52\% FVF rather than the 56-63\% sought after for the rest of the materials. Hence, the axial modulus, $E_{11}$, of $222 \mathrm{GPa}$ was relatively low for this $\mathrm{HM}$ material system. Note that a $65 \% \mathrm{FVF}$ would result in a $E_{11}$ of $276 \mathrm{GPa}$. Prepreg materials with a higher FVF were ordered for the following coupon batches to be tested, in order to take full advantage of the reinforcing fibers.

Table 1: Thin-ply materials and properties used for evaluation of the bending test method.

\begin{tabular}{|c|c|c|c|c|c|c|c|c|c|c|c|}
\hline Label & $\begin{array}{c}\text { Material } \\
\text { (fiber/resin) }\end{array}$ & $\begin{array}{c}\text { SPT } \\
\text { Fabric } \\
\text { Form } \\
\end{array}$ & $\begin{array}{l}\text { Width } \\
(\mathrm{mm})\end{array}$ & $\begin{array}{l}\text { FAW } \\
\left(\mathrm{g} / \mathrm{m}^{2}\right)\end{array}$ & $\begin{array}{c}\text { Ply AW } \\
\left(\mathrm{g} / \mathrm{m}^{2}\right)\end{array}$ & $\begin{array}{l}\text { FVF } \\
(\%)\end{array}$ & $\begin{array}{c}\text { Cured Ply } \\
\text { Thickness } \\
(\mu \mathrm{m})\end{array}$ & $\begin{array}{c}\mathrm{E}_{11} \\
(\mathrm{GPa})\end{array}$ & $\begin{array}{c}\varepsilon_{11, \mathrm{UT}} \\
(\%)\end{array}$ & $\begin{array}{c}\varepsilon_{11, \mathrm{UC}} \\
(\%)\end{array}$ & $\begin{array}{c}\text { Vendor } \\
\text { (fiber / resin) }\end{array}$ \\
\hline C & MR60H/PMT-F7 & UD & 50 & 38 & 58 & 56 & $40 \pm 5$ & 164.3 & 1.73 & 0.96 & $\begin{array}{c}\text { Oxeon / } \\
\text { Patz M\&T }\end{array}$ \\
\hline СHM & HS40/PMT-F7 & UD & 45 & 29 & 63 & 52 & $30 \pm 5$ & 221.7 & 1.01 & 0.56 & $\begin{array}{c}\text { Sakai Ovex / } \\
\text { Patz M\&T }\end{array}$ \\
\hline $\mathrm{PW}_{\mathrm{C}}$ & HTA40/PMT-F7 & PW & 1000 & 61 & 97 & 54 & $67 \pm 5$ & 69.4 & 1.48 & 0.90 & $\begin{array}{l}\text { The Composites } \\
\text { Store/ PatzM\&T }\end{array}$ \\
\hline
\end{tabular}

SpT-Spread-tow; UD-unidirectional; $P W$-plain weave. Note that the manufacturer's data sheet values for tensile failure strains, $\varepsilon_{11, U T}$, and compressive failure strains, $\varepsilon_{11, U C}$, are, in general, lower than the bending failure strains but are listed as a lower bound. 


\section{B. Laminates}

Flat coupons combining thin-ply materials from Table 1 were fabricated for several laminates of interest to evaluate and refine the large deformation bending test method presented here. These laminates were designed for highperformance rollable composite booms for small satellite applications ${ }^{15-19}$, having a thin-shell of just two or three plies. In the real application, the laminates are subjected to biaxial bending moments as the booms first get flattened, and then coiled about a perpendicular axis. As a first step, uniaxial bending loads are applied on flat specimens for evaluation of the CBT method. Future tests will evaluate cylindrical thin-shells with the CBT approach for completeness, as was done in Ref. 5 and 15 following other test methods.

Given the very low thicknesses of the constitutive prepreg materials used, the laminates under evaluation were thinner than most previously studied HSC laminates. A future effort will assess at what thickness range the failure modes start to change from those observed on the thin-regime to those of the thick-regime, which also depends on the ply material and laminate. Most of the laminates under study presented thin-regime failure modes when the number of total plies was less than six.

In general, the number of plies at each fiber orientation was doubled or tripled on the flat coupons. For example, LAM1 was fabricated as a 6-ply laminate of the same layup construction of the original 3-ply laminate, i.e. [ $\pm 45 \mathrm{PW}_{2}$ $\left./ 0_{2} / \pm 45 \mathrm{PW}_{2}\right]$. The total thicknesses of the original laminates were so thin that the failure radius of curvatures of the flexures would be very small and hard to investigate with the photogrammetry equipment used as part of the validation of the test method. Also the CBT fixture poses some restrictions on minimum gage length allowed before the clamping plates come into contact due to their thickness. However, the values of the bending stiffnesses can be scaled down by considering the cubed thickness ratio of the original laminate to that of the coupons tested. Further tests on more representative 2-3-ply-thick laminates are currently planned as there is more confidence on the test approach and methodology.

Laminates with a single lamina orientation were also tested to assess the bending properties and understand the failure mechanics of the constituent thin-ply materials of the laminates of interest. These laminates are shown in Table 2 as CUNI_IM, CUNI_HM, and CPW. These single-material laminates were fabricated in 4-9 plies to increase the thickness of the final coupons, and to assess any differences in the failure modes or flexural rigidity from the thinner versions to the thicker ones. The " $x$ " values listed in the material label identifies the total number of plies of the laminate.

Flat panels with the laminates of interest were cured inside an autoclave under a constant pressure of $100 \mathrm{KPa}$ (vacuum) with the temperature ramping to $180^{\circ} \mathrm{C}$ at $3{ }^{\circ} \mathrm{C} / \mathrm{min}$, and dwelling for $2 \mathrm{~h}$ as recommended by the resin manufacturer. This replicated the same out-of-autoclave fabrication cure process followed for the real application, deployable composite booms ${ }^{18}$. The use of the epoxy PMT-F7 resin enables adequate curing under vacuum bag conditions. The composite plaques were cured sandwiched between steel caul plates so that smooth surfaces are observed on both sides of the coupon. This provides different results than curing thin-shell booms, where the vacuum bag side of the laminate has a rough surface and the tool side has a smooth one. However, as the goal of this study was to, first, evaluate the CBT method and, second, the bending properties of the laminates, more symmetrical coupons were sought after to ease the process. Thus, future coupons will be fabricated without a top caul plate to evaluate more boom-like specimens and compare the results with these ones.

Table 2: Coupon Labeling and Test Matrix

\begin{tabular}{ccccc}
\hline \hline Label & Laminate & $\begin{array}{c}\text { Orientations } \\
\text { tested }\end{array}$ & $\begin{array}{c}\text { \# Coupons } \\
\text { per orient. }\end{array}$ & $\begin{array}{c}\text { Avg thickness } \\
(\boldsymbol{\mu m})\end{array}$ \\
\hline CUNI_IM_x4 & {$\left[0_{\mathrm{C}}\right]_{4}$} & $0,90,+45$ & $4,3,5$ & $166 \pm 3$ \\
CUNI_IM_x9 & {$[0 \mathrm{c}]_{9}$} & $0,90,+45$ & $4,3,4$ & $396 \pm 40$ \\
CUNI_HM_x4 & {$\left[0_{\mathrm{CHM}}\right]_{4}$} & $0,90,+45,-45$ & $4,4,6,6$ & $124 \pm 12$ \\
CPW_x3 & {$[0-90 \mathrm{PW}]_{3}$} & $0,90,+45$ & $4,4,4$ & $192 \pm 4$ \\
CPW_x8 & {$\left[0-90 \mathrm{PW}_{\mathrm{C}}\right] 8$} & $0,90,+45$ & $4,5,10$ & $574 \pm 53$ \\
LAM1_x6 & {$\left[ \pm 45 \mathrm{PWc}_{2} / \mathrm{Cc}_{2} / \pm 45 \mathrm{PWc}_{2}\right]$} & $0,90,+45$ & $5,6,8$ & $340 \pm 15$ \\
\hline
\end{tabular}

The composite panels were precision cut with a diamond saw blade into 38.1-mm-wide and 50.8-mm-long rectangular coupons with a dimensional tolerance of $0.1 \mathrm{~mm}$. Given the thinness of the composite panels, these had to be sandwiched between 2.5-mm-thick G10 fiberglass panels to guarantee parallelism, and avoid water lubrication intake or damage caused by the blade during the cutting process. Cutting coupons such that all edges are square was critical to obtaining valid test results.

Given that the bending stiffness was a strong function (cubic) of the laminate thickness, microscopy was used to accurately measure the ply thickness and total coupon thickness of at least half of the coupon batch for each laminate 
studied prior to the application of the surface coating needed for photogrammetry tracking. The coupons that were not measured were assigned the average thickness values computed from the population measured. However, for the CUNI_IM_x4, CP_x3, and LAM1_x6 panels five $12 \mathrm{~mm}$ x $12 \mathrm{~mm}$ squares were cut from various locations of the master panel to measure an average thickness for all test coupons. For every sample, micrographs were taken at four different regions spaced across the coupon width, where at least five measurements were taken at each section to find average ply and total thickness values per coupon.

For micrographing purposes, one of the short edges of the coupon was first polished with various levels of silicone carbide metallurgical paper of 400, 800 and 1200 grit, to produce a clear surface to view under an optical microscope. Images were taken at 100x and 200x magnification using a Reichert Jung MeF3A microscope with a Leica DFC450 camera to measure laminate thickness and microscopic geometric features (tow width, height, separation, wavelength, and crimp angle in PW spread-tow fabrics), and assessment of laminate quality, i.e. level of impurities like voids or resin rich areas. Figure 9 shows two typical micrographs taken for two different laminates. The results show good material and manufacturing consistency with a laminate thickness coefficient of variation of under $10 \%$ for all materials tested where, the thinner laminates carried the largest thickness variability.

Additional images were taken at a 500x magnification to determine the ply/laminate FVF through optical analysis by transforming the original images into high-contrast black-and-white images in ImageJ open software, and postprocessing them in Matlab by pixel-count histogram analysis.

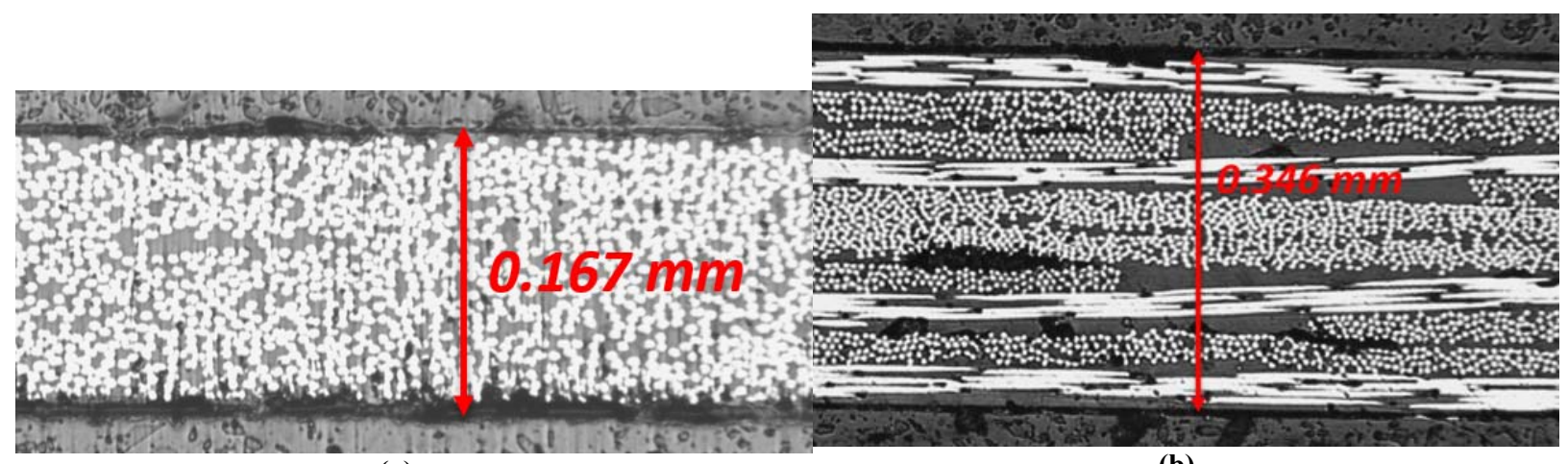

(a)

(b)

Fig. 9. Micrographs showing the measured total laminate thickness of: (a) [0c] 4 , CUNI_IM_x4 (MR60H /PMT-F7 UD); and (b) [ ${ }^{\left.45 P W c_{2} / 0 c_{2} / \pm 45 P c_{2}\right]}$, LAM1_x6, where the PW is HTA40 /PMT-F7 and the UD is $\overline{M R 60 H} / \mathrm{PMT}$-F7 from Table 1.

\section{Analysis Methods}

\section{A. Bending Stiffness Analysis}

In the CBT approach, the clamped boundary condition of the coupon and the kinematics of large inextensional bending deformations combine to prevent transverse curvature, $\kappa_{y}$, from developing due to Poisson effects. The test boundary conditions add artificial stiffness but classical lamination theory (CLT) shows they are adequate for measuring terms of the bending stiffness matrix, $D$. For the special case of a transversely isotropic material loaded in pure bending with the transverse curvature constraint to zero, the familiar $A B D$ matrix reduces to:

$$
M_{x}=D_{11} \kappa_{x} \text { and } M_{y}=D_{12} \kappa_{x}
$$

The direct output from the flexure test is moment versus curvature, which is related by the coupon flexural rigidity, $D_{11}$. For this bending test, the constant coupon curvature $(\kappa)$ assumed is $\kappa_{x}$ and the moment applied is $M_{x}$. The maximum moment at the coupon midgage length, $M_{\max }$, from Eq. 5 is used to calculate the stiffness in the principal loading direction, $D_{l 1}$. Herein, the test output will simply be referred to as the $M-\kappa$ curve. The slope of that curve determines the laminate stiffness following Eq. 7. In general, the $D_{l l}$ is computed by performing linear regressions on moving 5 data point windows of the test results.

Measured values will be compared with analytical results calculated with CLT analysis with the Kirchhoff thinplate theory, which includes micromechanical analysis to compute individual plies, and application of equal end moment assumptions leading to a constant curvature of the flexures.

As an example of the test results that have been gathered with the CBT method, Fig. 10 shows the maximum moment, $M_{\max }$, and bending stiffness in the coupon's axial 0 deg direction, $D_{11}$, for two thin-ply laminates of the same 
MR60H/PMT-F7 unidirectional material, but different number of plies (CUNI_IM_x4 and CUNI_IM_x9). Significant differences between the two laminates were observed. The thicker 9-ply coupon, with a total thickness of $395 \mu \mathrm{m}$, shows a fairly linear $M-\kappa$ curve resulting in an almost constant bending stiffness throughout the test. Whereas the thinner 4-ply coupon of $167 \mu \mathrm{m}$ thickness presented a nonlinear $M-\kappa$ curve resulting in a five-fold increase in bending stiffness during the test. These trends were observed on all four 0 deg coupons tested of the same construction, which also shared similar results. The final drop in the curves shown were due to specimen failure.

If the constant value of $D_{11}$ obtained for the thicker sample, $0.780 \mathrm{~N}-\mathrm{m}$, is scaled down to the smaller thickness using the cubed thickness ratio of the two specimens value of $0.059 \mathrm{~N}-\mathrm{m}$ is obtained for the thinner sample. This value was crossed during the last $5 \%$ of the test with the thinner coupon for curvatures above $250 \mathrm{~m}^{-1}$ or smaller radii of curvature less than $4 \mathrm{~mm}$, as can be seen in Fig. 1 (b). Reasons for the large stiffness nonlinearity measured in the thinner UD coupons, or why it appears like the true material stiffness was not achieved until high curvatures were reached were unverified but are most likely due to gravity. Comparing future test data gathered with the CWB CBT fixture would determine whether gravity effects influenced the results aforementioned for the thinner coupons with small gage lengths and assess true material nonlinear behavior.

The theoretical values of $D_{l 1}$ calculated using CLT analysis were $0.711 \mathrm{~N}-\mathrm{m}$ and $0.064 \mathrm{~N}-\mathrm{m}$ for these particular CUNI_IM_x9 and CUNI_IM x4 coupons. These numbers show small differences with respect to the measured average values over the last $5 \%$ of the test of $9.7 \%$ and $8.5 \%$. These differences are generally acceptable for most engineering purposes. Thus, the CBT method is a good candidate test for large deformation bending evaluation of thin unidirectional coupons until failure.

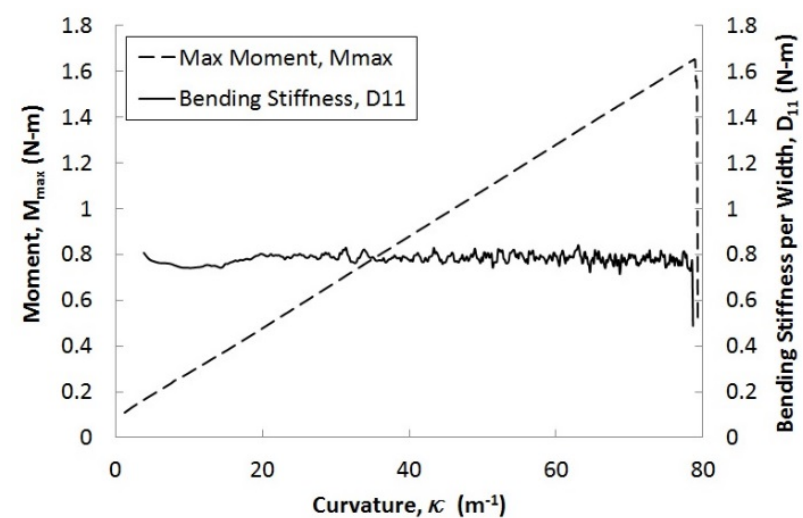

(a)

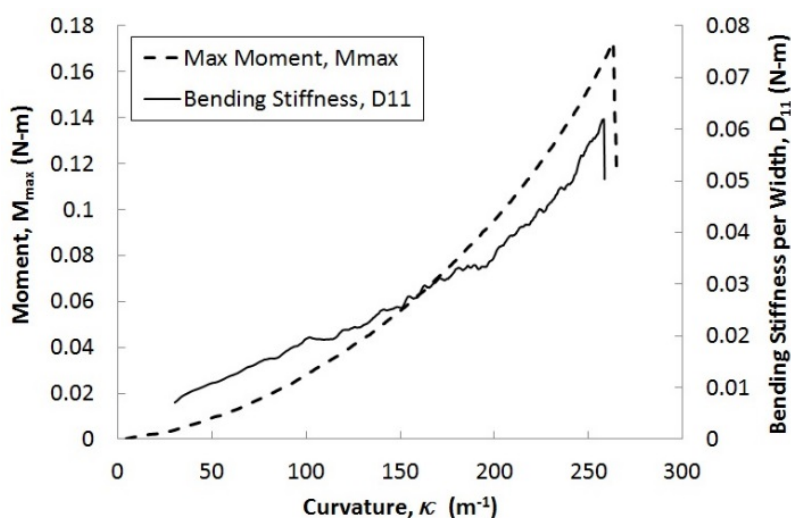

(b)

Fig. 10. M-k and $D_{11-k}$ curves for two MR60H/PMT-F7 [0 $]_{n}$ unidirectional laminates with (a) $n=9$, and (b) $n=4$ plies. The sudden drop in moment and stiffness at the end denotes fracture in the composite coupon.

\section{B. Digital Image Correlation for Strain and Rotation Angle Analysis}

To validate the assumptions of the nonlinear kinematic model that was used to compute the bending properties of the flexures from empirical parameters, digital image correlation (DIC) equipment was used to measure the full-field strain on at least one of the two sides of the laminate flexures. Two independent sets of DIC equipment, namely VIC 3D from Correlated Solutions ${ }^{22}$ and ARAMIS from $\mathrm{GOM}^{23}$, were used to evaluate the surface strain fields on the coupon during bending. Ultimately the average major strain, $\varepsilon_{11}$, values measured at the midgage section were compared with those computed with CLT at the same region $\left(M_{x}=M_{\max }\right)$ under the simplifying assumption of constant curvature throughout the coupon $\left(\kappa_{x}=\kappa\right)$; for reference see Eq. 2 and 4.

Figure 11 shows the principal surface strain, $\varepsilon_{11}$, values measured throughout the test for one of the thicker 9-ply unidirectional IM fiber coupons being tested in the 0 deg orientation. Given the nonlinear rotational kinematics of the CBT approach, the strain-vs-time curve is not linear, as shown in Fig. 11 (a). As expected for this orthotropic laminate and direction tested, the strain-vs-curvature curves were fairly linear throughout the test, particularly for the compressive side after the initial specimen buckling. This provides confidence in using the simple kinematic model from Eq. 4 and 7 for this case. Under this assumption, the slope of the $\varepsilon-\kappa$ curves in Fig. 11 (b) were half the coupon thickness $(t / 2)$.

The average measured surface strains at failure at the apex of the bent coupon were $1.98 \%$ and $1.75 \%$ for the compression and tension sides, with the coupons suffering from fiber tensile fracture. The compression strain value surpasses what would be expected from the fiber manufacturer's data sheet for much thicker coupons tested under uniaxial compression, which show a strain to failure of about $1 \%$. However, the tensile failure strain of $1.75 \%$ is in 
line with tensile coupon data tested at LaRC and the manufacturer's data sheet; see Table 1. This clearly shows that the tensioned fibers were able to stabilize the compressed fibers past their expected failure strains up to a point where the tensioned ones abruptly fail . In general for these thin UD coupons and with 0 deg test orientation, brush-like broken fibers were left on the tension side of the specimen while fibers on the compression side were still intact in some areas of the sample.

The significant differences in strain values obtained at both surfaces of the coupon was thought to be related to the shift in neutral axis that the specimen experiences during the large deformation bending test as a result of carbon fiber material nonlinearities at higher strains ${ }^{1,2,7}$. As the tensile side stiffens and the compressive side softens at high strains, the neutral axis moves towards the tension side, and thus the distance to the surface under tension diminishes, resulting in smaller strains when compared to those of the surface under compression. Thus, being able to measure these strains was critical in accurate modeling and performance predictions of the thin-ply flexures. The vertical test configuration of the CBT employed has proven helpful in capturing the distinct behavior of the flexure on both sides.

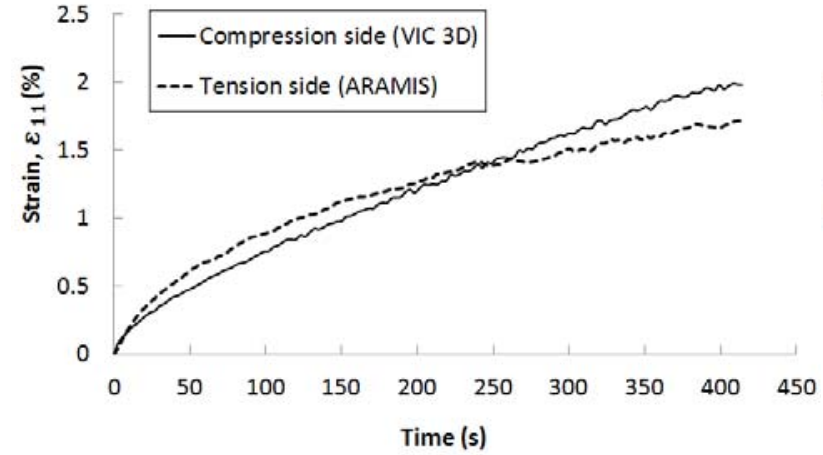

(a)

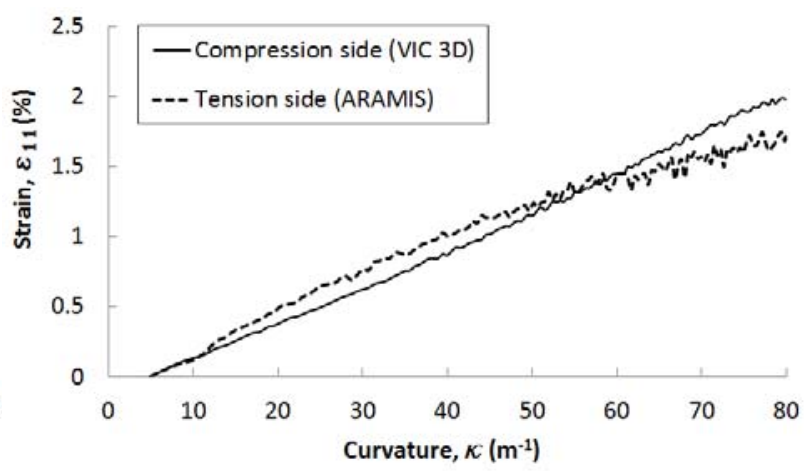

(b)

Fig. 11. Surface axial strains, e11, at both sides of a 0 deg 9-ply MR60H /PMT-F7 coupon vs (a) test time, and (b) curvature, $\boldsymbol{\kappa}$.

Image processing was also used to measure the rotation angle of the CBT fixture lower arm, $\boldsymbol{\phi} / \mathbf{2}$, during all tests. For this, a side view video camera records the lower arm as it rotates. The arm has a random speckled pattern section that serves as the target for the DIC photogrammetry system. Video footage was then transformed to still pictures at a predetermined rate and processed in VIC 2D from Correlated Solutions ${ }^{22}$ to obtain an accurate representation of the rotation involved. Figure 12 shows a comparison of the measured rotation angles of the arm for the same 9-ply UD coupon aforementioned and those calculated numerically by solving Eq. 1 . Both angles were very similar throughout the test, which validates the simple nonlinear kinematic equations of motion of the CBT method described above that assume a constant curvature for the coupon; see Eq. 2. Under this assumption, the slope of the linear $\phi / 2-\kappa$ curve in Fig. 12 (b) is constant and equal to half the coupon gage length $(s / 2)$. Similar results were obtained for all the coupons tested so far, where the angle difference was less than $3 \mathrm{deg}$. This further increases the confidence in the bending test method used.

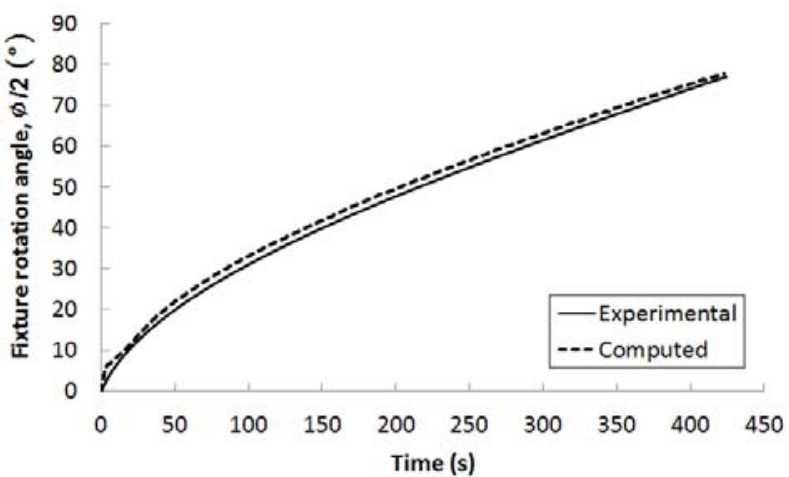

(a)

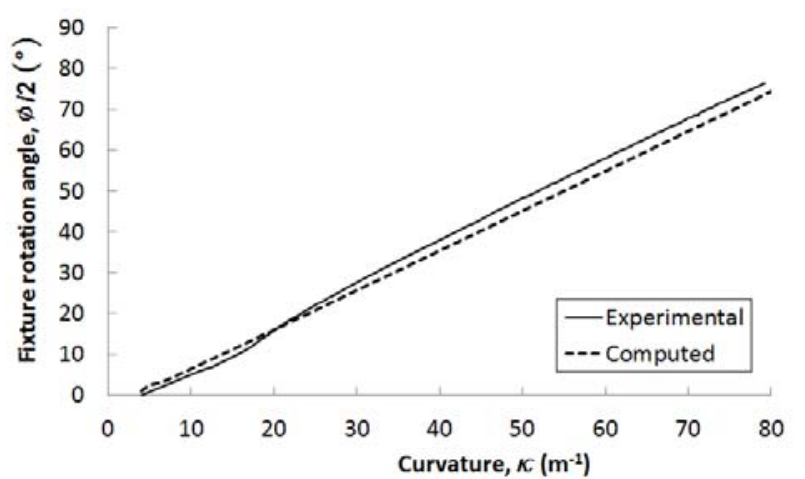

(b)

Fig. 12. Numerically computed vs measured angle of rotation of the lower fixture arm, $\phi / 2$, during a test vs (a) test time, and (b) coupon curvature, $\kappa$. 


\section{Test Results}

All of the tests presented in this section were carried out at NASA LaRC using the CBT method and two versions of the CBT fixtures, namely the (lighter) metal fixture (Fig. 4 (b)) and the (lightest) plastic fixture (Fig. 4 (c)), where only a limited number of tests used the new the counter-weight balanced (CWB) plastic fixture (Fig. 7) recently developed by Opterus R\&D. Tests where the CWB fixture was employed will be indicated.

\section{A. CUNI_IM}

The average measured bending properties for the IM MR60H/PMT-F7 unidirectional material tested are presented in Table 3. To calculate the initial and final bending stiffness of each coupon, the data points over the first and last 5\% of the test were averaged, and these average values were then used to compute the summary numbers listed below per test orientation. Figure 10 shows typical $\mathrm{M}-\mathrm{k}$ and $\mathrm{D}_{11-\mathrm{k}}$ curves obtained during the test of 0 deg coupons, and Figure 11 typical e $11-\mathrm{k}$ curves. In general, the bending response of the 4-ply coupons was significantly different from that of the 9-ply coupons. The former showed a highly nonlinear response, with a $5 \mathrm{x}$ and $3 \mathrm{x}$ increase in bending stiffness over the test for the 0 deg and 90 deg specimens, where expected values were only obtained towards the end of the test at high curvatures; See Fig. 10 (b). Reasons for this were unverified, but most likely due to gravity, rather than material behaviour. Further tests with additional coupons, other IM fibers, and the new CWB fixture will should reveal the true degree of material nonlinearity over the bending strain range. The 45 deg coupons showed similar nonlinear $\mathrm{D}_{11-\mathrm{K}}$ curves, but with a $40 \%$ decrease of bending stiffness as curvature increased. However, as shown in Fig. 10 (a), the thicker coupons present a smooth constant bending stiffness curve until failure, except for the $45 \mathrm{deg}$ off-axis coupons that showed nonlinear stiffening, and $D_{1 l}$ values were what was to be expected.

Table 3: Measured and CBT calculated properties for the MR60H/PMT-F7 unidirectional coupons tested.

\begin{tabular}{|c|c|c|c|c|c|c|}
\hline CUNI_IM_ & $\mathrm{x} 4$ & $\mathbf{x 9}$ & $\mathbf{x 4}$ & $\mathbf{x 9}$ & $\mathbf{x 4}$ & $\mathbf{x} 9$ \\
\hline Orientation $\left({ }^{\circ}\right)$ & $\mathbf{0}$ & $\mathbf{0}$ & 90 & 90 & +45 & +45 \\
\hline Avg Peak Maximum Moment, $M_{\max }(\mathrm{N}-\mathrm{m})$ & 0.1756 & 1.6169 & 0.0140 & 0.2784 & 0.0256 & 0.0696 \\
\hline Std Dev (N-m) & 0.0029 & 0.0313 & 0.0012 & 0.0057 & 0.087 & 0.0105 \\
\hline Coeff of Variation $(\%)$ & 1.6 & 1.9 & 8.4 & 2.1 & 34.1 & 15.2 \\
\hline Avg Maximum/Failure Curvature, $\kappa\left(\mathrm{m}^{-1}\right)$ & 257.2 & 79.62 & 107.4 & 42.0 & 103.0 & 38.9 \\
\hline Std Dev $\left(\mathrm{m}^{-1}\right)$ & 9.6 & 2.4 & 0.5 & 3.5 & 10.6 & 4.4 \\
\hline Coeff of Variation $(\%)$ & 3.7 & 3.0 & 0.5 & 8.2 & 10.3 & 11.4 \\
\hline Avg Initial Bending Stiff per Width, $D_{11}$ (N-m) & 0.0115 & 0.7203 & 0.0032 & 0.2372 & 0.0410 & 0.0557 \\
\hline Std Dev $(\mathrm{N}-\mathrm{m})$ & 0.0013 & 0.0217 & 0.0001 & 0.0226 & 0.0005 & 0.0037 \\
\hline Coeff of Variation $(\%)$ & 11.2 & 3.0 & 3.0 & 9.5 & 13.6 & 6.7 \\
\hline Avg Final Bending Stiff per Width, $D_{11}$ (N-m) & 0.0618 & 0.7739 & 0.0090 & 0.2485 & 0.0258 & 0.1548 \\
\hline Std Dev $(\mathrm{N}-\mathrm{m})$ & 0.0025 & 0.0169 & 0.0001 & 0.0020 & 0.0077 & 0.0232 \\
\hline Coeff of Variation $(\%)$ & 4.0 & 2.2 & 1.1 & 0.8 & 30.0 & 15.0 \\
\hline Avg Tensile Strain at Failure, $\varepsilon_{11, T}(\%)$ & 1.08 & 1.72 & 0.73 & 1.11 & 0.67 & 0.68 \\
\hline Std Dev $(\%)$ & 0.03 & 0.3 & 0.07 & 0.08 & 0.07 & 0.09 \\
\hline Coeff of Variation (\%) & 2.6 & 17.4 & 9.5 & 7.2 & 10.6 & 12.7 \\
\hline Avg Compression Strain at Failure, $\varepsilon_{11, \mathrm{C}}(\%)$ & & 2.05 & & 1.27 & & 1.08 \\
\hline Std Dev (\%) & -- & 0.065 & -- & 0.13 & -- & 0.02 \\
\hline Coeff of Variation (\%) & & 3.18 & & 10.0 & & 1.9 \\
\hline \multicolumn{7}{|l|}{ Failure Mode: } \\
\hline Side: $\mathrm{T}$ - Tension; C - Compression; B - Both. & $\mathrm{T}$ & $\mathrm{T}$ & $\mathrm{B}$ & $\mathrm{B}$ & $\mathrm{B}$ & $\mathrm{B}$ \\
\hline Crack propagation angle $\left({ }^{\circ}\right)$ & 90 & 90 & 90 & 90 & +45 & +45 \\
\hline Section: G - Grip; B; Middle - M; E-Edges. & M & M & $\mathrm{G}, \mathrm{M}$ & $\mathrm{G}, \mathrm{M}$ & $\mathrm{E}, \mathrm{M}$ & $\mathrm{E}, \mathrm{M}$ \\
\hline Progressive: $\mathrm{Y}$ - Yes; N - No. & $\mathrm{N}$ & $\mathrm{N}$ & $\mathrm{Y}$ & $\mathrm{Y}$ & Y & Y \\
\hline
\end{tabular}

Contrary to traditional thick composite behavior, the average strains measured at the state of failure for the on-axis 9-ply UD laminates were significantly larger in compression than in tension $(2.05 \%$ vs $1.72 \%)$. This shows that carbon fiber nonlinearity shifts the neutral axis of bending towards the tension side, where fibers get progressively stiffer as the internal graphite crystallites tend to rotate and align more with the fiber axis, as previously observed ${ }^{1,2,13}$. As formerly reported for this material system, the failure tensile strains measured with CBT in 0 deg coupons were in line with the values reported by the fiber manufacturer Grafil's data sheet for uniaxial tensile tests performed at 0 deg on much thicker coupons ${ }^{24}$; see Table 1 . However, the compression failure strains measured under flexural conditions were twice of the reported in uniaxial compression tests. This means that for the thin-regime, unidirectional fibers 
attained abnormally higher strains in bending when the fibers in the tension side were able to increase the local shear stiffness of the fibers on the compression side thereby preventing failure under the modes experienced on thicker laminates (e.g. micro-buckling). Both thickness IM coupons (4-ply and 9-ply) tested at 0 deg failed at the coupon midgage by brittle fracture along the transverse direction of the tensile fibers with representative whisker-like fracture profiles. Most of the compression side remained intact at this point, revealing a thin-regime failure mode. For the 9ply coupons at $90 \mathrm{deg}$, the average maximum tensile strain measured of $1.11 \%$ obtained with CBT matches the value of $1.08 \%$ reported in Grafil's 90 deg uniaxial tension test ${ }^{24}$. In this case, failure occurred mostly at the grips but also at the coupon center. In either way, a transverse crack through the coupon thickness propagated along the coupon width, splitting the coupon into two parts.

The average tensile failure strains measured for the 4-ply laminates were significantly below the numbers measured on the 9-ply coupons ( $1.08 \%$ vs $1.72 \%$ at $0 \mathrm{deg}$ and $0.73 \%$ vs $1.11 \%$ at $90 \mathrm{deg})$. Premature failure on the thinner 0 deg coupons was likely the cause of the highly nonlinear response observed in the coupon principal directions as strain levels increased. The thinner $90 \mathrm{deg}$ coupons failed prematurely at lower curvatures than expected, given the very low transverse stiffness of the UD laminates. Results for the thinner coupons were consistent thoughout and show variations of less than $10 \%$. The failure tensile strains measured for the $45 \mathrm{deg}$ bias specimens were similar for both thickness coupons $(0.67 \%$ vs $0.68 \%)$. Note that these were the principal strains (i.e. at 0 deg), while the actual strains in the fiber direction ( $45 \mathrm{deg}$ ) would be about half. Such low consistent values at both thickness ranges were due to the low shear stiffness of unidirectional coupons, promoting the progressive damage observed, starting at the coupon edges and propagating at a $45 \mathrm{deg}$ angle. Comparing all the computed average curvatures at failure clearly demonstrates that the 90 deg and 45 deg coupons fail prematurely due to the UD laminate's low transverse and shear stiffness, and are not taking full advantage of the fiber properties as 1) the values for the two orientations were similar in both thickness coupons reflecting the onset of a similar lower-strain failure mode; and 2) those values should be higher and closer to the maximum curvatures of 0 deg coupons. The on-axis sample curvatures were approximately $2.5 \mathrm{x}$ and $2 \mathrm{x}$ larger for the 4-ply and 9-ply coupons, respectively.

A possible reason for the disparity between the measured failure strain values of thinner and thicker unidirectional 0 deg and 90 deg coupons not investigated would be that the thinner samples were fabricated or cut with some degree of fiber misalignment. On-axis loading tests, very thin laminates can be prone to premature failure if small fiber misalignment is present, as interpreted from the off-axis orientation sample results discussed. Another reason would be that thickness non-uniformity was present, and had not been captured in the micrographs taken at one of the coupon edges. This would cause stress concentrations in discrete areas with the latter being a common disadvantage of current spread-tow thin-ply materials, which has a larger effect as the number of plies diminishes.

Compression strain failure was not measured for the thinner 4-ply laminates as the gage length was very small, preventing the DIC system from viewing the last stages of the test when failure occurs. Fixture refinement was produced accordingly to increase the viewing capability of the compression side of ultrathin coupons in future tests.

Table 4: Measured and predicted bending stiffness and strains for the MR60H/PMT-F7 unidirectional coupons tested.

\begin{tabular}{|c|c|c|c|c|c|c|}
\hline CUNI_IM_ & $\mathbf{x 4}$ & $\mathbf{x 9}$ & $\mathbf{x 4}$ & $\mathbf{x 9}$ & $\mathbf{x 4}$ & $\mathbf{x 9}$ \\
\hline Orientation $\left({ }^{\circ}\right)$ & $\mathbf{0}$ & $\mathbf{0}$ & 90 & 90 & +45 & +45 \\
\hline "Measured Avg Bending Stiff per Width, $D_{11}(\mathrm{~N}-\mathrm{m})$ & 0.0618 & 0.7739 & 0.0032 & 0.2485 & 0.0258 & 0.1548 \\
\hline Predicted Avg Bending Stiff per Width, $D_{11}(\mathrm{~N}-\mathrm{m})$ & 0.0629 & 0.7161 & 0.0030 & 0.0344 & 0.0191 & 0.2178 \\
\hline$\%$ Difference & 1.8 & 8.1 & 6.7 & 722.4 & 35.1 & 40.7 \\
\hline Measured Avg Tensile Strain at Failure, $\varepsilon_{11, \mathrm{~T}}(\%)$ & 1.08 & 1.72 & 0.73 & 1.11 & 0.67 & 0.68 \\
\hline Measured Avg Compression Strain at Failure, $\varepsilon_{11, \mathrm{C}}(\%)$ & -- & 2.05 & -- & 1.27 & -- & 1.08 \\
\hline Predicted Principal Surface Strains at Avg Max Curv, \& (\%) & 2.13 & 1.57 & 0.89 & 0.83 & 0.85 & 0.77 \\
\hline$\%$ Difference in Tension & 97.7 & 8.3 & 22.1 & 25.1 & 27.6 & 13.3 \\
\hline \% Difference in Compression & -- & 23.1 & -- & 34.5 & -- & 28.7 \\
\hline
\end{tabular}

Table 4 presents the bending stiffness, $D_{l l}$, values calculated using rule of mixtures and CLT analyses considering the ply properties from Table 1, and average laminate thicknesses (166 $\mu \mathrm{m}$ for 4-ply and $396 \mu \mathrm{m}$ for 9-ply coupons) from Table 2. The computed bending stiffnesses for the 0 deg coupons compare favorably with the average measured values, with differences of about $2 \%$ and $8 \%$ for the 4-ply and 9-ply samples. The differences are acceptable for most engineering purposes, and reflect that the CBT may be able to predict accurately the principal bending stiffness of unidirectional flexures even for ultrathin designs. The off-axis stiffnesses show more differences. The initial bending stiffness of the 90 deg thinner coupons, which are the $D_{22}$ term of the 0 deg coupons, were in good agreement with the predicted value and is the one presented in the Table 4 instead of the final average $D_{l l}$ value. Due to the progressive failure observed on the $90 \mathrm{deg}$ coupon, it is more realistic to assume the initial $D_{l l}$ value for this orientation. The 
difference for the 9-ply coupons at 90 deg was abnormally large (722\%) and the $D_{22}$ measured for the thinner laminates should be assumed and scaled up. The computed $D_{11}$ for the 45 deg coupons show $35 \%$ and $40 \%$ differences with respect to the average measured results for the 4-ply and 9-ply samples.

The predicted surface principal strains at the point of maximum curvature achieved (failure) presented in Table 4 were calculated using Eq. 4, assuming constant curvature of the sample and a linear material model (no shift in the neutral axis occurs during bending). These assumptions lead to some error and the values provided should only be indicative for trend evaluation. In general, the differences between predicted and measured tensile surface strains at failure were smaller for the 9-ply coupons, with maximum differences of up to $35 \%$ for the 9-ply coupons at $90 \mathrm{deg}$. The measured tensile strains for the 4-ply coupon were lower than the predicted ones, while the measured tensile and compression strains for the thicker 9-ply coupons were under predicted by the model. The average value of tensile strain of $1.08 \%$ measured on the 0 deg coupons was unrealistically low for the curvature the coupon was sustaining at the point of failure, and could be the part of the reason for the difference in strain results with the 9-ply specimens. The CBT model predicted surface strain of $2.13 \%$ was more realistic compared to the response observed for the thicker coupons, and may be used to define an upper limit for the thin-regime failure strain envelope for the material. It is possible that localized curvatures were occurring in coupon areas close to the grips due to gravity sagging of the fixture arms inducing shear, particularly for the thinner coupons, and the region of interest (midgage) used to measure the strains with DIC was not representative of the maximum curvature/strains achieved. In summary, it appears that further tests are required to evaluate the assumption of constant curvature at large rotation angles of the arms $\left(\phi / 2>75^{\circ}\right)$ when using weight-unbalanced CBT fixtures in a vertical test configuration to test very thin coupons.

\section{B. CUNI_HM}

Most of the column bending tests for the high modulus (HM) HS40/PMT-F7 unidirectional material were carried out at LaRC with the new CWB test fixture, and only three samples of the +45 and -45 deg coupons employed the weight-unbalanced plastic fixture for comparison. Figure 7 shows a 0 deg coupon bending test with the CWB plastic fixture. Note that these flexures were the thinnest tested so far with an average thickness of $124 \mu \mathrm{m}$. The average measured bending properties for the 4-ply HM unidirectional material tested are presented in Table 5. To calculate the initial and final bending stiffnesses of each coupon, the points over the first and last $5 \%$ of the test were averaged, and these average values were then used to compute the final numbers listed below per test orientation.

The 0 deg coupons present a farely smooth and constant $\mathrm{D}_{11-\mathrm{k}}$ curve over the bending test. As with the IM fiber tests, failure occurs in the tension side and presents brittle whisker-shape damage that abruptly propagates in the transverse direction. Both grip and midgage section failures were observed. The 90 deg coupons presented jagged $\mathrm{D}_{11-\mathrm{K}}$ curves with a $3 \mathrm{x}$ reduction in bending stiffness over the test indicative of progressive failure, with the material failing from the beginning of the test. Both grip and midgage section failures were observed. The bending response of the +45 and -45 deg coupons was similar, also showing jagged D ${ }_{11-\mathrm{K}}$ curves. The response obtained with the two CBT fixtures employed was different. The coupons tested with the CWB fixture increased the $D_{l l}$ over the test by $2 \mathrm{x}$ and $3 \mathrm{x}$ for the +45 and $-45 \mathrm{deg}$ coupons, whereas the coupons tested with the weight unbalanced plastic fixture decreased the stiffness by $2.5 \mathrm{x}$. However, the final $D_{l l}$ values for both test fixtures tended to converge. Both grip and midgage section failures were observed on the $+45 \mathrm{deg}$ and -45 deg coupons. The specimens showed signs of initial failure at the edges of the midgage section which propagated to the grips along the off-axis fiber direction.

The average curvatures at failure computed have low coefficients of variation. Contrary to the observations from IM unidirectional coupons test results, the maximum curvatures for +45 and -45 deg specimens were similar to the 0 deg ones. The 90 deg coupons showed even larger curvatures, which did not translate to larger tensile strains, revealing disparities from the simplifying assumptions (constant curvature and linear material) made in those cases.

Table 6 presents the bending stiffness, $D_{11}$, values calculated using rule of mixtures and CLT analyses considering the ply properties from Table 1 and an average laminate thickness of $124 \mu \mathrm{m}$ from Table 2 . The CLT computed and CBT measured bending stiffnesses for the 0 deg and 90 deg coupons show differences of $29 \%$ and $37 \%$. Although these differences were larger than those found for the IM unidirectional coupons tested, they were still acceptable for most engineering purposes. One reason for this disparity could be the larger coefficient of variation (10\%) observed for the HM laminate thickness that was used for computed predictions.

The predicted surface principal strains at the point of failure presented were again calculated using Eq. 4, which assumed constant curvature of the sample and a linear material model. The 0 deg coupons show very good agreement between the predicted values and those measured at the coupon tension side $(0.92 \%$ vs $0.91 \%)$. These were slightly lower than the tensile failure strains from the manufacturer datasheet ${ }^{25}(1.01 \%)$, that was reported for $60 \% \mathrm{FVF}$ specimens. Since these specimens have a $52 \%$ FVF, slightly lower values were expected. The compression side strain values were not measured but were expected to be even larger than these given fiber nonlinearity at large strains. The fact that the 0 deg coupons failed in a brittle tension mode means that, for these very thin HM unidirectional flexures, 
the tension side fibers were also able to stabilize the compression side ones, enabling larger strains than expected under pure compression loading $(0.56 \%)$; see Table 1 . The 90 deg coupons show less agreement between predicted and measured values, likely the result of the progressive failure observed on these coupons. The average strain at failure values for the +45 and -45 deg coupons predicted and measured were in good agreement, with a maximum of $20 \%$ difference for the -45 deg coupons tested with the weight unbalanced fixture. The same orientation coupons tested with the CWB fixture only show $1 \%$ discrepancy.

Comparing the test results with both CBT fixtures used shows that the CWB fixture allow larger curvatures before failure as gravity induced moments were minimized. The measured maximum principal tensile strains obtained with the weight-unbalanced fixture were slightly higher than those of the CWB fixture. However, there was a larger disparity with respect to the predicted values, which were also lower. A reason for this could be that the weightunbalanced fixture was inducing small localized curvatures near the bottom grip caused by some degree of fixture sagging, ultimately leading to the larger DIC strain measurements and errors with the computed constant curvatures. Therefore, it was thought that the CWB fixture enables a more robust column bending test by promoting loading conditions (pure bending) closer to those wanted.

Table 5: Measured and CBT calculated properties for the HS40/PMT-F7 unidirectional coupons tested.

\begin{tabular}{|c|c|c|c|c|c|c|}
\hline CUNI_HM_ & $\mathbf{x 4}$ & $\mathrm{x} 4$ & $\mathbf{x 4}$ & $\mathrm{x4}$ & $\mathbf{x 4}$ & $\mathbf{x 4}$ \\
\hline Orientation $\left({ }^{\circ}\right)$ & $\mathbf{0}$ & 90 & +45 & +45 & -45 & -45 \\
\hline Fixture Used & CWB & CWB & CWB & Plastic & CWB & Plastic \\
\hline "Avg Peak Maximum Moment, $M_{\max }(\mathrm{N}-\mathrm{m})$ & 0.0877 & 0.0239 & 0.0100 & 0.0638 & 0.0187 & 0.0623 \\
\hline Std Dev (N-m) & 0.0114 & 0.0006 & 0.0051 & 0.0024 & 0.0051 & 0.0024 \\
\hline Coeff of Variation $(\%)$ & 13.0 & 2.4 & 8.4 & 3.72 & 27.4 & 3.9 \\
\hline Avg Maximum/Failure Curvature, $\kappa\left(\mathrm{m}^{-1}\right)$ & 131.1 & 149.8 & 137.7 & 111.6 & 128.4 & 119.0 \\
\hline Std Dev $\left(\mathrm{m}^{-1}\right)$ & 4.2 & 12.4 & 11.6 & 2.7 & 12.6 & 6.4 \\
\hline Coeff of Variation $(\%)$ & 3.2 & 8.3 & 8.4 & 2.4 & 0.8 & 5.4 \\
\hline Avg Initial Bending Stiff per Width, $D_{11}(\mathrm{~N}-\mathrm{m})$ & 0.0262 & 0.0074 & 0.0032 & 0.0253 & 0.0032 & 0.0261 \\
\hline Std Dev $(\mathrm{N}-\mathrm{m})$ & 0.0041 & 0.0004 & 0.0000 & 0.0010 & 0.0003 & 0.0004 \\
\hline Coeff of Variation $(\%)$ & 15.7 & 5.6 & 0.5 & 4.1 & 9.6 & 1.4 \\
\hline Avg Final Bending Stiff per Width, $D_{11}(\mathrm{~N}-\mathrm{m})$ & 0.0273 & 0.0026 & 0.0064 & 0.0108 & 0.0092 & 0.0117 \\
\hline Std Dev (N-m) & 0.0031 & 0.0005 & 0.0013 & 0.0005 & 0.0014 & 0.0010 \\
\hline Coeff of Variation $(\%)$ & 11.4 & 18.9 & 19.9 & 4.7 & 14.8 & 8.3 \\
\hline Avg Tensile Strain at Failure, $\varepsilon_{11, \mathrm{~T}}(\%)$ & 0.91 & 0.64 & 0.81 & 0.84 & 0.91 & 1.00 \\
\hline Std Dev $(\%)$ & 0.14 & 0.14 & 0.00 & 0.01 & 0.02 & 0.13 \\
\hline Coeff of Variation $(\%)$ & 15.8 & 21.6 & 0.05 & 1.4 & 2.3 & 13.0 \\
\hline \multicolumn{7}{|l|}{ Failure Mode: } \\
\hline Side: $\mathrm{T}$ - Tension; $\mathrm{C}$ - Compression; B - Both. & $\mathrm{T}$ & $\mathrm{B}$ & $\mathrm{B}$ & $\mathrm{B}$ & $\mathrm{B}$ & $\mathrm{B}$ \\
\hline Crack propagation angle $\left(^{\circ}\right)$ & 90 & 90 & +45 & +45 & -45 & -45 \\
\hline Section: G - Grip; B; Middle - M; E- Edges. & G & $\mathrm{G}, \mathrm{M}$ & $\mathrm{G}, \mathrm{M}$ & $\mathrm{G}, \mathrm{M}$ & $\mathrm{E}, \mathrm{M}$ & $\mathrm{E}, \mathrm{M}$ \\
\hline Progressive: $\mathrm{Y}-$ Yes; $\mathrm{N}-$ No. & $\mathrm{N}$ & $\mathrm{Y}$ & $\mathrm{Y}$ & Y & $\mathrm{Y}$ & $\mathrm{Y}$ \\
\hline
\end{tabular}

Table 6: Measured and predicted bending stiffness and strains for the HS40/PMT-F7 unidirectional coupons tested.

\begin{tabular}{|c|c|c|c|c|c|c|}
\hline CUNI_HM_ & $\mathbf{x 4}$ & $\mathrm{x} 4$ & $\mathbf{x 4}$ & $\mathrm{x4}$ & $\mathbf{x 4}$ & $\mathbf{x 4}$ \\
\hline Orientation $\left({ }^{\circ}\right)$ & $\mathbf{0}$ & 90 & +45 & +45 & -45 & -45 \\
\hline Fixture Used & CWB & CWB & CWB & Plastic & CWB & Plastic \\
\hline "Measured Avg Bending Stiff per Width, $D_{11}(\mathrm{~N}-\mathrm{m})$ & 0.0273 & 0.0026 & 0.0064 & 0.0108 & 0.0092 & 0.0117 \\
\hline Predicted Avg Bending Stiff per Width, $D_{11}(\mathrm{~N}-\mathrm{m})$ & 0.0353 & 0.0019 & 0.0098 & 0.0098 & 0.0098 & 0.0098 \\
\hline$\%$ Difference & 29.3 & 36.8 & 53.1 & 10.2 & 6.5 & 19.38 \\
\hline Measured Avg Tensile Strain at Failure, $\varepsilon_{11, \mathrm{~T}}(\%)$ & 0.91 & 0.64 & 0.81 & 0.84 & 0.91 & 1.00 \\
\hline Predicted Principal Surface Strains at Avg Max Curv, \& (\%) & 0.92 & 1.05 & 0.96 & 0.78 & 0.90 & 0.83 \\
\hline \% Difference in Tension & 1.64 & 63.9 & 18.5 & 7.7 & 1.2 & 20.5 \\
\hline
\end{tabular}

\section{C. $\mathbf{C P W}$}


All of the column bending tests for the standard modulus HTA40/PMT-F7 spread-tow plain weave material were carried out with the weight-unbalanced lightest metal and plastic test fixtures, except for the \pm 45 deg coupons of the 3 -ply batch that required very small gage lengths $(<8 \mathrm{~mm})$ to cause specimen failure, enabled by the new CWB fixture. The flexural response of the thinner 3-ply CPW samples was nonlinear. The $\mathrm{D}_{11-\mathrm{k}}$ curves obtained in all three orientations tested $(0,90$ and $+45 \mathrm{deg})$ show some degree of nonlinearity, where bending stiffness values increase over the test. Figure 13 (a) shows the maximum moment and bending stiffness graphs versus coupon curvature measured ( $\mathrm{M}_{\max }-\mathrm{K}$ and $\mathrm{D}_{11-\mathrm{K}}$ curves) for all five 3-ply coupons tested at $90 \mathrm{deg}$. Given the structural symmetry of the plain weave material, which had the same number of weft and warp fiber tows, the bending behavior of the 0 deg coupons was very similar and expected (i.e. $\mathrm{D}_{11} \approx \mathrm{D}_{22}$ ), where the small differences were likely caused by variability in the coupon population, or some minor degree of misalignment when cutting the coupons. An order of magnitude (10-12x) increment in bending stiffness was measured over the test for the 3-ply 0-90 deg specimens. Aside from fiber nonlinearity, this stiffening effect, as curvature increases, could be partially caused by the microstructure of the PW lamina itself. As curvature and strain increase, friction within the three-dimensional grillage of tows may get progressively larger, preventing relative motion between adjacent tow surfaces. On the contrary, the 8-ply coupons, which achieved $2.5 \mathrm{x}$ smaller principal strain levels, present near constant $\mathrm{M}-\mathrm{k}$ and $\mathrm{D}_{11-\mathrm{k}}$ curves. The average maximum moment and bending stiffness values calculated for the first and last $5 \%$ of the test are reported in Table 7 .

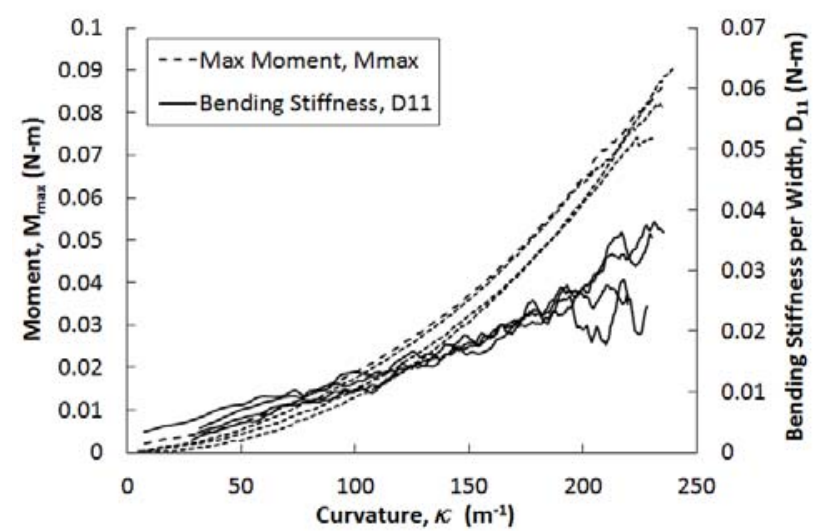

(a)

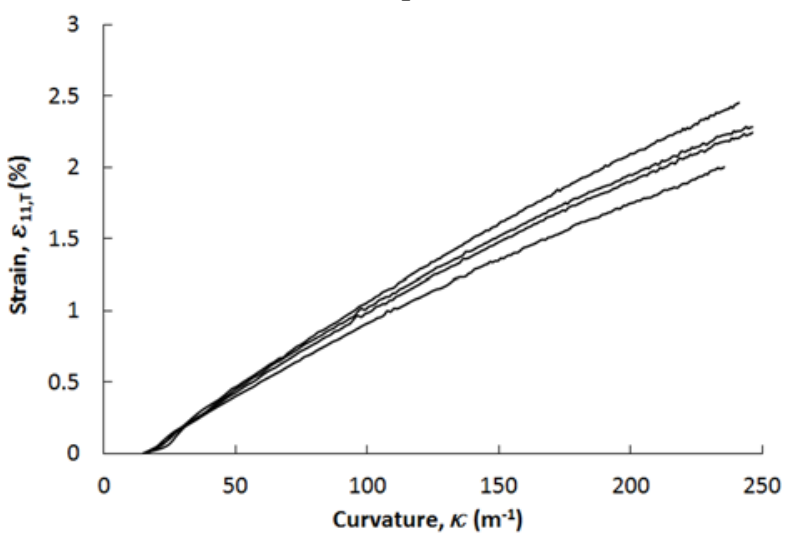

(b)

Fig. 13. Measured output test data for all the $90 \mathrm{deg} C P W_{-} x 3$ coupons: (a) $M_{\max }-\mathrm{K}$ and $D_{11-\mathrm{K}}$ curves; (b) Tensile surface

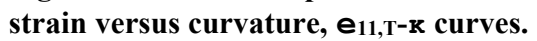

The failure mode of the 3-ply, 0-90 deg coupons was different than their 8-ply counterparts. The thinner coupons failed at the midgage section of the tension side revealing thin-regime failure, with several 90 deg specimens failing at the grip through the coupon thickness. Figure 13 (b) shows the measured bending strains at the tension side of the $90 \mathrm{deg}$ coupons, which show an average value of $2.24 \%$. The $e_{11-\mathrm{k}}$ curves present some degree of nonlinearity related to the material stiffening effect aforementioned. In general, these strains were all significantly higher than the tensile failure strain of $1.46 \%$ measured on tensile coupons of the same material, and properties tested at LaRC following the ASTM D3039 standard ${ }^{28}$. Since the failure mode was in tension, the weave geometry was clearly enabling larger tensile strains in bending than in uniaxial tension. However, the thicker 8-ply coupons bent, failed on the compression side as expected in thick-regime behavior. The uniaxial compression failure strain reported for this material is about $0.9-1 \%$, which coincides with the strain values measured on the tension side of the thicker coupon during bending. The compression side values attained were slightly higher (1.1-1.2\%), and clearly the tension side fibers were still stabilizing the compression fibers preventing them from early failure, even for thicker coupons. However, this stabilizing effect was less pronounced than for the 3-ply CPW samples or the other UD materials tested, where larger compression strains in bending were achieved in comparison with their reported compression failure strains.

The response of the $\pm 45 \mathrm{deg}$ coupons was highly matrix dependent. As oppose to the $0-90$ coupons, the $\mathrm{D}_{11-\mathrm{VS}-\mathrm{k}}$ response for both thinner and thicker +45 deg batches show jagged curves with fairly constant average $D_{I I}$ values over the test. These coupons achieved curvatures 1.5-2.25x that of the 0-90 coupons. As the principal axis of bending was offset $45 \mathrm{deg}$ from the fibers, the principal strains measured should be about twice of that experienced in the fiber direction. This was clear from looking at the average tensile strain at the moment of failure from Table 7 for both thickness coupons: $1.78 \%$ vs $0.9 \%$ on CPW_x 3 and $4.4 \%$ vs $2.25-2.7 \%$ on CPW_x 3 for 45 deg and $0-90$ deg coupons. The rest of the average measured bending properties for all the CPW laminates tested are also presented in Table 7. 
Both the thinner and thicker 45 deg coupons failed at the midgage section of the compression side with zigzag cracks propagating at +45 and -45 deg.

Figure 14 shows the bending strains measured with the two DIC systems at the last stage before failure for the tension (ARAMIS) and compression (VIC 3D) sides of a CPW_x8 coupon tested at 0 deg. The full-field strain measurement allows evaluation of the constant curvature assumption for every coupon tested. In general, the difference in average value obtained from evaluating different regions at the coupon midgage section was less than $\pm 0.05 \%$ strain ( $\sim 5 \%$ of the average strain measurement). Also these average values do not differ by more than $\pm 0.2 \%$ strain ( $\sim 20 \%$ of the average value) from the rest of the coupon area. This means that the strain field was relatively constant over the specimen, as expected for the column bending test. The large strain concentrations near the grips shown in Fig. 14 (b) were not realistic, and were related to VIC 3D algorithm errors when large out-of-plane distortion of the centroids of each speckle tracked occur.

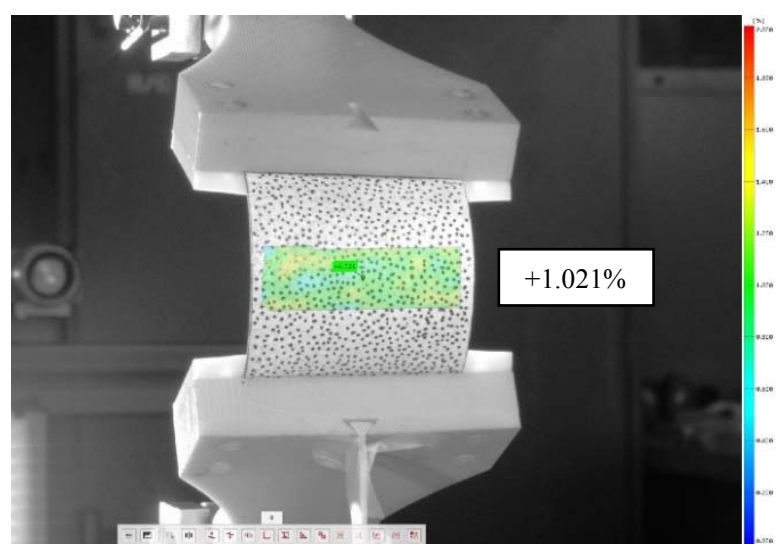

(a)

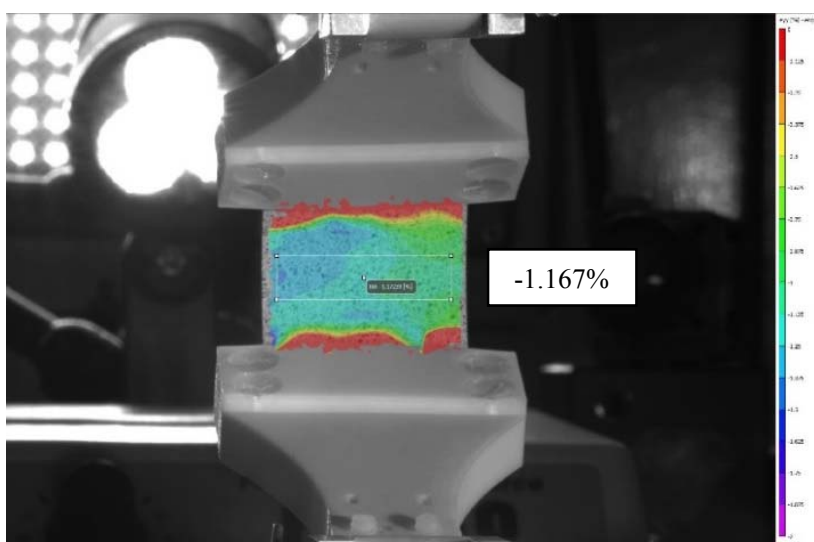

(b)

Fig. 14. Full-field bending surface strains measured at the last stage before failure and average value (white box) at the midgage section for a CPW_x8 coupon: (a) tension side (ARAMIS); and (b) compression side (VIC 3D). Failure occurred at the compression side. The lightest plastic CBT fixture was used for this particular sample. The strain contour maps have a strain range of $0 /+2 \%$ in (a) and $0 /-2 \%$ in (b).

Table 7: Measured and CBT calculated properties for the HTA40/PMT-F7 plain weave coupons tested.

\begin{tabular}{|c|c|c|c|c|c|c|}
\hline $\mathbf{C P W}$ & $\mathbf{x} 3$ & $\mathbf{x 8}$ & $\mathbf{x} 3$ & $\mathbf{x 8}$ & $\mathbf{x} 3$ & $\mathbf{x 8}$ \\
\hline Orientation $\left({ }^{\circ}\right)$ & $\mathbf{0}$ & $\mathbf{0}$ & 90 & 90 & +45 * & +45 \\
\hline Avg Peak Maximum Moment, $M_{\max }(\mathrm{N}-\mathrm{m})$ & 0.0993 & 0.8084 & 0.0910 & 0.8825 & 0.2002 & 0.9505 \\
\hline Std Dev (N-m) & 0.0060 & 0.0188 & 0.0164 & 0.0590 & 0.0068 & 0.0564 \\
\hline Coeff of Variation (\%) & 5.7 & 2.3 & 18.1 & 6.7 & 3.4 & 5.9 \\
\hline Avg Maximum/Failure Curvature, $\kappa\left(\mathrm{m}^{-1}\right)$ & 208.4 & 42.5 & 235.9 & 45.1 & 346 & 95.0 \\
\hline Std Dev $\left(\mathrm{m}^{-1}\right)$ & 10.5 & 3.8 & 8.1 & 2.9 & 12.21 & 5.6 \\
\hline Coeff of Variation $(\%)$ & 5.0 & 9.0 & 3.5 & 6.4 & 3.7 & 5.9 \\
\hline Avg Initial Bending Stiff per Width, $D_{11}$ (N-m) & 0.0037 & 0.6776 & 0.0037 & 0.7152 & 0.0272 & 0.3806 \\
\hline Std Dev $(\mathrm{N}-\mathrm{m})$ & 0.0005 & 0.0106 & 0.0012 & 0.0444 & 0.0006 & 0.0192 \\
\hline Coeff of Variation $(\%)$ & 13.3 & 1.6 & 33.5 & 6.2 & 2.3 & 5.1 \\
\hline Avg Final Bending Stiff per Width, $D_{11}$ (N-m) & 0.0443 & 0.7057 & 0.0367 & 0.7068 & 0.0267 & 0.4001 \\
\hline Std Dev (N-m) & 0.0054 & 0.0248 & 0.0061 & 0.0576 & 0.0040 & 0.0208 \\
\hline Coeff of Variation $(\%)$ & 12.3 & 3.5 & 16.6 & 8.2 & 15.1 & 5.2 \\
\hline Avg Tensile Strain at Failure, $\varepsilon_{11, \mathrm{~T}}(\%)$ & 2.70 & 0.89 & 2.24 & 0.90 & 4.40 & 1.78 \\
\hline Std Dev $(\%)$ & 0.22 & 0.11 & 0.18 & 0.11 & 0.30 & 0.22 \\
\hline Coeff of Variation $(\%)$ & 8.2 & 12.3 & 8.0 & 12.2 & 6.8 & 12.3 \\
\hline Avg Compression Strain at Failure, $\varepsilon_{11, \mathrm{C}}(\%)$ & & 1.07 & & 1.16 & & 2.65 \\
\hline Std Dev $(\%)$ & -- & 0.06 & -- & 0.03 & -- & 0.15 \\
\hline Coeff of Variation $(\%)$ & & 6.0 & & 2.5 & & 5.7 \\
\hline \multicolumn{7}{|l|}{ Failure Mode: } \\
\hline Side: $\mathrm{T}$ - Tension; $\mathrm{C}$ - Compression; B - Both. & $\mathrm{T}$ & $\mathrm{C}$ & $\mathrm{B}$ & $\mathrm{C}$ & $\mathrm{C}$ & $\mathrm{C}$ \\
\hline Crack propagation angle $\left(^{\circ}\right)$ & 90 & 90 & 90 & 90 & \pm 45 & \pm 45 \\
\hline Section: G - Grip; B; Middle - M; E-Edges. & M & $\mathrm{M}, \mathrm{G}$ & $\mathrm{G}, \mathrm{M}$ & $\mathrm{M}, \mathrm{G}$ & $\mathrm{M}$ & $\mathrm{M}$ \\
\hline Progressive: $\mathrm{Y}$ - Yes; N - No. & $\mathrm{N}$ & $\mathrm{N}$ & $\mathrm{N}$ & $\mathrm{N}$ & $\mathrm{N}$ & $\mathrm{N}$ \\
\hline
\end{tabular}


Table 8 shows the measured and predicted average bending stiffnesses and strains for all the CPW coupons tested. In general, the values predicted using the built-in micromechanical plain weave model from Autodesk Helius Composite 2016 were slightly overestimating the $D_{l l}$ values with respect to those measured. The woven ply model was built using the average ply thicknesses from Table 2 and the measured average FVF of 54\% from Table 1 that led to the woven ply axial modulus property of 64.9 GPa presented in Table 1. The HTA40 fiber and PMT-F7 matrix properties used were those listed in the Toho Tenax ${ }^{28}$ and $\mathrm{PMT}^{29}$ data sheets, respectively.

Differences exist between spread-tow plain weave fabric geometry and the general plain weave model from Helius, and that could be leading to the slightly higher stiffness values for the predicted $D_{11}$. Another cause for this difference, particularly for the \pm 45 deg coupons, may be that the epoxy matrix materials exhibit reduced shear stiffness at higher strains, and large shear strains are present at this test orientation. Therefore, a reduced matrix shear modulus should be used when calculating the PW lamina properties for CLT analysis ${ }^{14}$. Considering such a reduction in matrix shear modulus will have a great effect on the coupling terms of the laminate ABD stiffness matrix, and in particular the $D_{l 1}$ at a 45 deg orientation. Table 8 also shows reduced bending stiffness values, herein referred to as $D_{I I}{ }^{*}$, computed assuming a three order of magnitude reduction in PMT-F7 matrix shear modulus, $G_{12}$, (1.12 GPa vs $\left.1.12 \mathrm{MPa}\right)$. The computed reduced $D_{11}{ }^{*}$ with the matrix high strains assumption compare more favorably with the measured bending stiffness values than the previous predictions without any shear modulus reduction. As expected, the effect on the 0 $90 \mathrm{deg}$ coupons was negligible with the difference decreasing by $0.3 \%$. However, the effect on the 45 deg coupons for both plies was substantial. The measured and reduced predicted values for CPW_x8 specimens match, and the difference for the CPW_x8 coupons decreases by $6 \%$ to a value of $9.5 \%$. The artificial prediction increment in the weave extensional and transverse modulus properties, due to weave undulation and tow geometry differences between the micromechanical woven-ply model and the actual spread-tow material, was likely the largest remaining source of discrepancy in the bending stiffnesses, particularly for the $0-90$ orientation.

The predicted principal surface strains at the average maximum curvature show relatively good agreement with the DIC-measured average values at the tensile side of the coupon. The difference with the compression side strain values of the thicker 8-ply coupons were higher (21-29\%). The largest difference shown of 32\% for the 3-ply coupons at $45 \mathrm{deg}$, could be attributed to the very small view area for the VIC 3D system, and any localized curvatures that formed towards the bottom grip would affect the strain measurements. The coupon radius of curvature was less than 3-4 mm towards the end of the test. Future tests with the new CWB fixtures will evaluate this effect on ultrathin coupons that require tiny gage lengths for failure.

Table 8: Measured and predicted bending stiffness and strains for the HTA40/PMT-F7 plain weave coupons tested.

\begin{tabular}{|c|c|c|c|c|c|c|}
\hline $\mathbf{C P W}_{2}$ & $\mathbf{x 3}$ & $\mathbf{x 8}$ & $\mathbf{x} 3$ & $\mathbf{x 8}$ & $\mathbf{x} 3$ & $\mathbf{x 8}$ \\
\hline Orientation $\left({ }^{\circ}\right)$ & $\mathbf{0}$ & $\mathbf{0}$ & 90 & 90 & +45 & +45 \\
\hline "Measured Avg Bending Stiff per Width, $D_{11}(\mathrm{~N}-\mathrm{m})$ & 0.0443 & 0.7224 & 0.0367 & 0.6974 & 0.0231 & 0.4001 \\
\hline Predicted Avg Bending Stiff per Width, $D_{11}(\mathrm{~N}-\mathrm{m})$ & 0.0410 & 0.7771 & 0.0410 & 0.7771 & 0.0267 & 0.4377 \\
\hline$\%$ Difference & 8.0 & 7.6 & 11.7 & 11.4 & 15.6 & 9.4 \\
\hline Predicted Avg Reduced* Bending Stiff per Width, $D_{11}{ }^{*}(\mathrm{~N}-\mathrm{m})$ & 0.0409 & 0.7752 & 0.0409 & 0.7752 & 0.0211 & 0.3999 \\
\hline$\%$ Difference & 8.3 & 7.3 & 11.4 & 11.1 & 9.5 & 0.1 \\
\hline Measured Avg Tensile Strain at Failure, $\varepsilon_{11, \mathrm{~T}}(\%)$ & 2.70 & 0.89 & 2.24 & 0.90 & 4.40 & 1.78 \\
\hline Measured Avg Compression Strain at Failure, $\varepsilon_{11, \mathrm{C}}(\%)$ & -- & 1.07 & -- & 1.16 & -- & 2.65 \\
\hline Predicted Principal Surface Strains at Avg Max Curv, \& (\%) & 2.00 & 0.84 & 2.26 & 0.89 & 3.32 & 1.89 \\
\hline \% Difference in Tension & 25.9 & 5.4 & 1.1 & 0.8 & 32.5 & 5.7 \\
\hline \% Difference in Compression & -- & 21.35 & -- & 23.0 & -- & 29.0 \\
\hline
\end{tabular}

*Assumes a reduced (three orders of magnitude smaller)matrix shear modulus.

\section{LAM1}

The 6-ply $\left[ \pm 45 \mathrm{PWc}_{2} / 0 \mathrm{c}_{2} / \pm 45 \mathrm{PWc}_{2}\right]$ symmetric balanced laminate with the plain weave HTA40/PMT-F7 surface plies and the unidirectional MR60H/PMT-F7 central plies, referred to herein as LAM1_x6, was one of the laminates of interest at NASA for deployable boom applications ${ }^{18}$ to induce bistability on these thin-shell composite structures ${ }^{19}$.

All of the column bending tests for the LAM1_x6 were carried out with the weight-unbalanced test fixtures. The $\mathrm{D}_{11-\mathrm{K}}$ curves obtained in all three orientations tested $(0,90$ and $+45 \mathrm{deg})$ show some degree of nonlinearity, where stiffness increased with curvature over the test by two-fold for the 0 deg and 90 deg specimens, and approximately $50 \%$ for the 45 deg coupons. The smaller increment in bending stiffness of the 45 deg coupons was attributed to the outer surface woven plies that were now oriented at 0-90 deg and, as observed for the 0 deg and 90 deg CPW_x8 
coupons, the bending response should be more linear. Figure 15 (a) shows the $\mathrm{M}-\mathrm{k}$ and $\mathrm{D}_{11-\mathrm{k}}$ curves for all five 0 deg specimens tested. Table 9 shows the measured and CBT calculated properties for all the LAM1_x6 coupons evaluated.

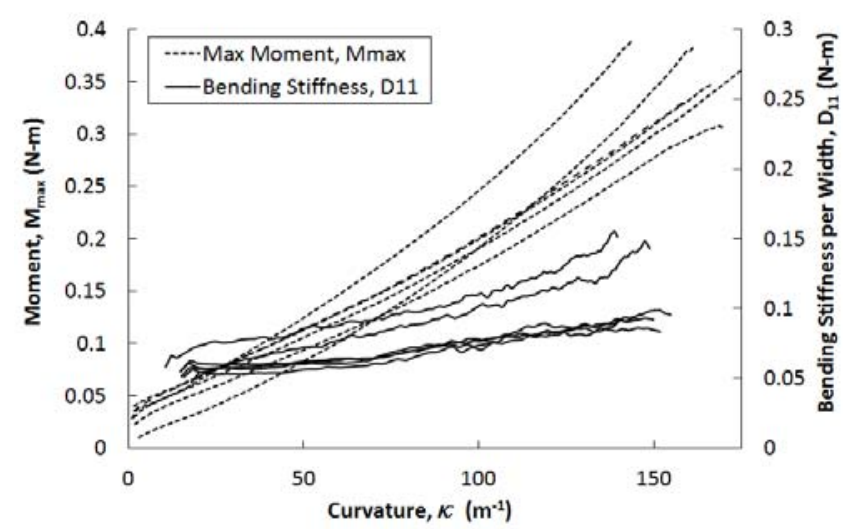

(a)

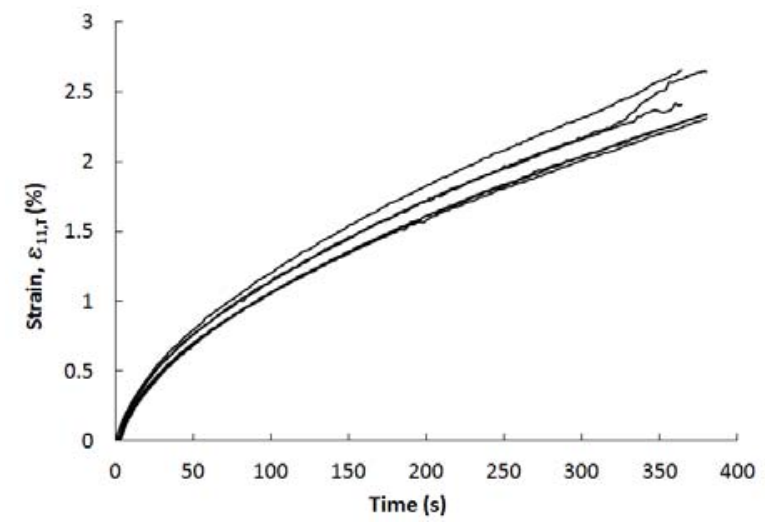

(b)

Fig. 15. Measured data for the 0 deg LAM1_x6 coupons: (a) $M_{\max -\mathrm{K}}$ and $D_{11-\mathrm{K}}$ curves; (b) Tensile surface strains, e $11, \mathrm{~T}$.

All samples broke at the compression side, usuallyat the midgage section. For the 0 deg and 90 deg coupons zigzag cracks on the woven plies under compression formed and propagating in the tow \pm 45 deg directions. For the $45 \mathrm{deg}$ coupons, the failure on the 0-90 deg woven plies under compression quickly propagated at $90 \mathrm{deg}$. The curvatures achieved for the 0 deg and 90 deg specimens were very similar, showing that the surface woven \pm 45 deg plies were the ones dictating the maximum curvatures allowed for the laminate, with the thinner central UD plies having less effect. These curvatures were about $70 \%$ larger than that of the average failure curvatures of the $45 \mathrm{deg}$ orientation coupons. This was expected given the orientation of the woven plies in each case.

The tensile surface strains measured over the bending test for all the 0 deg coupons were shown in Fig. 15 (b). An average value of $2.26 \%$ was found for the five specimens tested. The maximum tensile surface strains for the $90 \mathrm{deg}$ coupons observed were similar $(2.15 \%)$. Compression surface strains were expected to be larger than these because of laminate nonlinearity at large strains. Figure 16 shows the tensile strains in bending measured with VIC 3D at the last stage before failure for a 0 deg (a) and $45 \mathrm{deg}$ (b) LAM1_x6 coupon. These two coupons used the same gage length and the bent angle subtended by the $0 \mathrm{deg}$ coupon was larger, as evidenced from the two images. As for the UD and PW specimens (see Fig. 14), the strain field measured was nearly constant (within approximately 20\%) away from the limits of the evaluation area that were prone to software algorithm errors. Again, this means that the specimens were being subjected to pure bending with the CBT method with a minor moment gradient across the coupon.

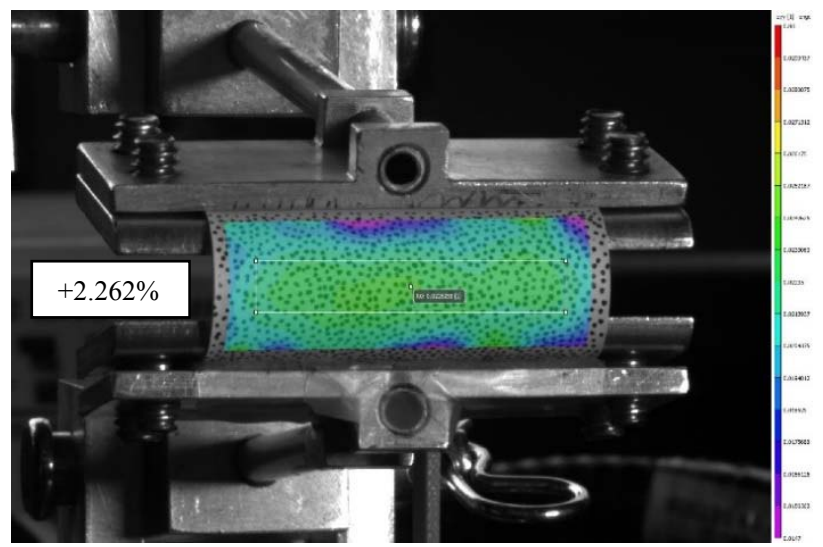

(a)

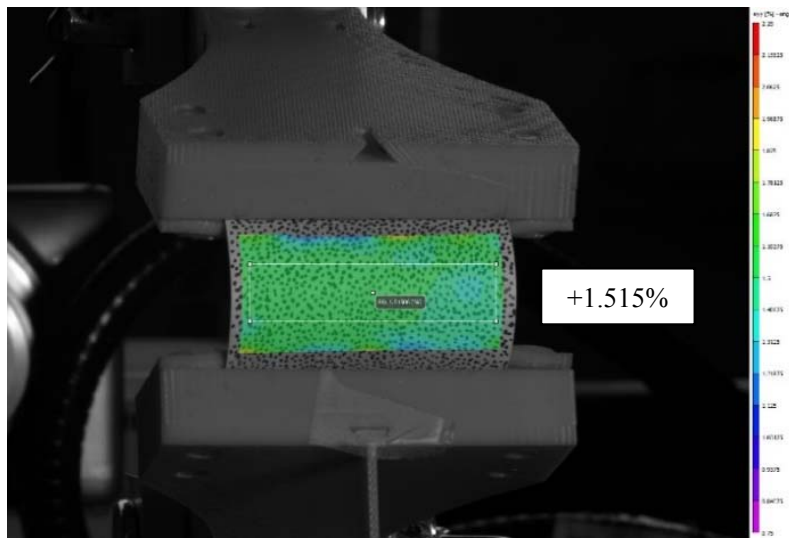

(b)

Fig. 16. Tensile surface strains measured with VIC 3D at the last stage before failure and average value (white box) at the coupon midgage section for two LAM1_x6 coupons oriented at: (a) 0 deg and tested with the metal fixture; and (b) 45 deg and tested with the plastic fixture. The strain contour maps have a strain range of $1.5-3.0 \%$ in (a) and $0.75-2.25 \%$ in (b).

Table 10 shows the predicted average surface strains by the CBT model and those measured at the tension side of the coupons bent. Generally, the computed principal surface strains at the average maximum curvature overestimate 
the DIC-measured values. The 0 deg and 90 deg coupons present less agreement with differences of $17 \%$ and $26 \%$. The 45 deg coupons failed at an average tensile surface strain of $1.45 \%$ and show a $9 \%$ difference with respect to predicted values. The measured values of the tensile surface strains at the moment of failure in the 6-ply LAM1 coupons, for every orientation tested, were within the strain range measured at the tensile side of the 3-ply and 8-ply CPW coupons of the same constitutive HTA40/PMT-F7 woven materials considering the 45 deg shift due to the LAM1 layup. For completeness, Table 10 also shows the predicted principal surface strains at the moment of failure for the two central UD plies. The strain values of $0.32 \%, 0.33 \%$ and $0.19 \%$ for the $0 \mathrm{deg}, 90 \mathrm{deg}$ and $45 \mathrm{deg}$ coupons were low enough not to cause failure in the MR60H/PMT-F7 UD plies, as can be deduced from evaluating the surface tensile strain values at failure, previously shown in Table 4 for CUNI_IM_x4.

Table 10 also presents the measured and predicted average bending stiffnesses and strains for all the LAM1_x6 coupons tested. Once more, CLT was used to do the layup and calculate the coefficients of the laminate stiffness $A B D$ matrix after the Helius's micromechanical fabric builder tool was used to model the woven plies from the data in Table 1 and 2 for the CPW laminates. Again, the predictions using Helius overestimate the bending stiffness values with respect to the measurements. The disparity in the $D_{l I}$ value for LAM1 was about $10 \%$. The average $D_{l 1}$ value of LAM1 measured on the $45 \mathrm{deg}$ orientation coupons shows a $16 \%$ difference with the predictions. The laminate $D_{22}$ value shows the largest discrepancy of $51 \%$. Repeating the same process followed for analyzing the CPW response, assuming a three order of magnitude reduction in the PMT-F7 matrix shear modulus, results in a much better agreement for the $D_{11}$ and $D_{22}$ stiffnesses of the LAM1 laminate $(1.4 \%$ and $38.3 \%)$. This was due to the reduction in axial and transverse stiffness for the surface woven \pm 45 deg plies at large strains.

Table 9: Measured and CBT calculated properties for the LAM1_x6 coupons tested.

\begin{tabular}{|c|c|c|c|}
\hline LAM1_ & $\mathbf{x 6}$ & x6 & x6 \\
\hline Orientation $\left({ }^{\circ}\right)$ & $\mathbf{0}$ & 90 & \pm 45 \\
\hline Avg Peak Maximum Moment, $M_{\max }(\mathrm{N}-\mathrm{m})$ & 0.3393 & 0.2558 & 0.4235 \\
\hline Std Dev (N-m) & 0.0334 & 0.0126 & 0.0364 \\
\hline Coeff of Variation $(\%)$ & 9.8 & 4.9 & 8.6 \\
\hline Avg Maximum/Failure Curvature, $\kappa\left(\mathrm{m}^{-1}\right)$ & 156.0 & 159.4 & 92.9 \\
\hline Std Dev $\left(\mathrm{m}^{-1}\right)$ & 10.6 & 14.8 & 7.8 \\
\hline Coeff of Variation $(\%)$ & 6.8 & 9.3 & 8.4 \\
\hline Avg Initial Bending Stiff per Width, $D_{11}(\mathrm{~N}-\mathrm{m})$ & 0.0571 & 0.042 & 0.1305 \\
\hline Std Dev (N-m) & 0.0068 & 0.0046 & 0.0133 \\
\hline Coeff of Variation $(\%)$ & 11.9 & 11.0 & 10.2 \\
\hline Avg Final Bending Stiff per Width, $D_{11}(\mathrm{~N}-\mathrm{m})$ & 0.1205 & 0.0830 & 0.1936 \\
\hline Std Dev $(\mathrm{N}-\mathrm{m})$ & 0.0209 & 0.0128 & 0.0205 \\
\hline Coeff of Variation $(\%)$ & 24.17 & 15.4 & 10.6 \\
\hline Avg Tensile Strain at Failure, $\varepsilon_{11, T}(\%)$ & 2.26 & 2.15 & 1.45 \\
\hline Std Dev (\%) & 0.11 & 0.08 & 0.08 \\
\hline Coeff of Variation $(\%)$ & 4.9 & 3.7 & 5.7 \\
\hline \multicolumn{4}{|l|}{ Failure Mode: } \\
\hline Side: $\mathrm{T}$ - Tension; $\mathrm{C}$ - Compression; $\mathrm{B}$ - Both. & $\mathrm{C}$ & $\mathrm{C}$ & $\mathrm{C}$ \\
\hline Crack propagation angle $\left(^{\circ}\right)$ & \pm 45 & \pm 45 & 90 \\
\hline Section: G-Grip; B; Middle - M; E-Edges. & $\mathrm{M}$ & M & $\mathrm{G}, \mathrm{M}$ \\
\hline Progressive: Y - Yes; N - No. & $\mathrm{N}$ & $\mathrm{N}$ & $\mathrm{N}$ \\
\hline
\end{tabular}

Table 10: Measured and predicted bending stiffness and strains for the LAM1_x6 coupons tested.

\begin{tabular}{|c|c|c|c|}
\hline $\begin{array}{l}\text { LAM1_- } \\
\text { Orientation }\left({ }^{\circ}\right)\end{array}$ & $\begin{array}{c}x 6 \\
0\end{array}$ & $\begin{array}{l}\mathbf{x 6} \\
90\end{array}$ & $\begin{array}{c}x 6 \\
\pm 45\end{array}$ \\
\hline Measured Avg Bending Stiff per Width, $D_{11}(\mathrm{~N}-\mathrm{m})$ & 0.1205 & 0.0830 & 0.1936 \\
\hline Predicted Avg Bending Stiff per Width, $D_{11}(\mathrm{~N}-\mathrm{m})$ & 0.1330 & 0.1256 & 0.2246 \\
\hline$\%$ Difference & 10.4 & 51.3 & 16.0 \\
\hline Predicted Avg Reduced* Bending Stiff per Width, $D_{11}{ }^{*}$ (N-m) & 0.1222 & 0.1148 & 0.2241 \\
\hline$\%$ Difference & 1.4 & 38.3 & 16.0 \\
\hline Measured Avg Tensile Strain at Failure, $\varepsilon_{11, \mathrm{~T}}(\%)$ & 2.26 & 2.15 & 1.45 \\
\hline Predicted Principal Laminate Surface Strains at Avg Max Curv, \& (\%) & 2.65 & 2.71 & 1.58 \\
\hline$\%$ Difference in Tension & 17.3 & 26.0 & 8.9 \\
\hline Predicted Principal Surface Strains at Avg Max Curv for central UD plies, \&UD (\%) & 0.32 & 0.33 & 0.19 \\
\hline
\end{tabular}

*Assumes a reduced (three orders of magnitude smaller)matrix shear modulus. 


\section{Conclusions}

A simple test method for large deformation bending of thin high strain composite flexures was presented. The test, referred to as the Column Bending Test (CBT), combined the best features of the platen test and the large deformation four point bending tests. This test fixture generated a coupon stress state that was maximum at the coupon midgage section (as in the platen test), decreasing to $80-90 \%$ of the maximum at the coupon grips. In contrast, the stress in the platen test reduces to zero where the coupon touches the platens. In the CBT, the stress state was mostly uniform, allowing a simple kinematic analysis to estimate moments and curvatures. Because the curvature was reduced at the grips, failure was more likely to occur in the coupon center (as opposed to the large deformation four-point bending test). This paper investigated using image processing and full-field strain measurements to evaluate the assumptions and nonlinear kinematic equations that represented the test method.

Gravity effects on weight-unbalanced vertical test configurations were studied. The gravity-induced shear loads and moments at the coupon edges that tend to cause sagging of the fixture at large angles of rotation were characterized. It was found that these depend on three test parameters: the fixture mass, the fixture arm length, and the coupon gage length. The fixture-dependent parameters (mass and length) were directly proportional to the gravity-induce loads and moments, while the opposite was true for the coupon gage length. This means that thinner coupons, that need smaller gage lengths to fail during a bending test, were actually more prone to gravity loading effects than thicker coupons. Thus, weight-balanced fixtures were needed when evaluating ultrathin flexures. The counterweight-balanced (CWB) fixture produced was capable of evaluating ultrathin $(<0.2 \mathrm{~mm})$ coupons up until failure, where previous unbalanced fixture designs could not, enabling $10-20 \%$ increase in coupon curvatures before failure on off-axis high modulus CFRP unidirectional flexures, while keeping a near constant curvature across the specimen. The latter was evidenced by the smaller difference between the surface strains measured and predicted with the constant curvature assumption with the fixture that was weight-balanced. Photogrammetry planar tracking of the two fixture arms during tests revealed that, even for the thinner specimens tested, the difference in rotation angle of each arm were within 4 deg throughout the test with this CWB fixture, and were within 3 deg from the calculated ones with the CBT kinematic nonlinear model. For CFRP laminates thicker than $0.35 \mathrm{~mm}$, the weight-unbalanced plastic fixture induced grip failure during some tests. The lightest metal fixture produced was able to induce midgage length failures on these thicker coupons, sometimes allowing for larger strains before failure.

One intermediate modulus unidirectional material (MR60H/PMT-F7), one high modulus unidirectional material (HS40/PMT-F7), one intermediate modulus plain weave material (HTA40/PMT-F7), and one intermediate modulus laminate built with these unidirectional and plain weave plies were evaluated using the CBT method. Coupons were tested in the 0,90 , and 45 deg orientations to evaluate any difference in bending behavior or limitations in the CBT approach. The coupons were micrographed prior to testing to accurately measure ply and total thicknesses, as well as fiber volume fractions with further image processing. The output data curves of the CBT, M-k, $\mathrm{D}_{11-\mathrm{k}}$, and $\mathrm{e}_{11-\mathrm{k}}$, were evaluated for every thin-ply material system, orientation and laminate thickness. Large nonlinearities in the bending response were identified for some of the thinner materials as well as laminates with off-axis \pm 45 deg woven plies.

The MR60H/PMT-F7 UD material showed the largest nonlinear behavior for on-axis $(0 \mathrm{deg})$ coupons at 4-ply thicknesses $(0.166 \mathrm{~mm})$ with a $\sim 5 \mathrm{x}$ increase in bending stiffness as curvature increased. Future tests carried out with the CWB fixture will evaluate how much of that effect is actually due to fiber nonlinearity, as similar recent tests carried with the CWB fixture for the very thin $(0.124 \mathrm{~mm})$ HS40/PMT-F7 UD material did not show that large stiffening effect. This suggests that gravity effects may have influenced the data for the thinner IM UD tests. Both of these very thin unidirectional material flexures and the thinner 3-ply HTA40/PMT-F7 woven laminates failed in a brittle tensile mode in bending, with surface strain values similar or even higher to those reported by the fiber manufacturer for uniaxial tensile tests. For all these thin-regime failure mode cases, the compression strains in bending, which were thought to be larger than the tensile strains in bending given material nonlinearity effects, were larger than the manufacturer data sheet values for pure compression tests. This means that thin flexures are able to attain significantly higher bending strains as the tensile side stabilizes the fibers under compression by increasing their local transverse and shear stiffness. This helps prevent micro-buckling at the strain levels anticipated for thicker composites samples. In contrast to the thinner laminates, the thicker on-axis 9-ply MR60H/PMT-F7 UD coupons and the 8-ply HTA40/PMT-F7 PW specimens repeatedly failed at the compression side of the bent specimen. This was consistent with expected thick-laminate failure mode behavior. Maximum failure strains achieve at the compression side were in line with those from reported values under uniaxial testing. Additional CBT tests will be able to identify for every material system and laminate, at what thickness range the 
failure mode behavior changes from the thin-regime to the thick-regime in order to take full advantage of the material nonlinearity.

The failure mode for the 6-ply $\left[ \pm 45 \mathrm{PWc}_{2} / 0 \mathrm{c}_{2} / \pm 45 \mathrm{PWc}_{2}\right]$ laminate (LAM1) in all orientations tested in bending was found to be compression failure of the inner woven plies. Failure strain values were in between those measured for the thinner 3-ply and thicker 8-ply HTA40/PMT-F7 woven coupons. Ignoring total laminate thickness constraints, the fact that the two MR60H/PMT-F7 unidirectional axial plies in the laminate center were subjected to low strains in bending gives room to maximize their number/thickness in order to increase the laminate stiffness, while not impacting much the maximum failure curvature.

The full-field bending strain measurements taken with DIC systems at one or both sides of the coupon allowed for the evaluation of the constant curvature assumption used in the simple kinematic model for the CBT method. The difference in average value obtained from evaluating different regions at the coupon midgage section was less than $5 \%$. Also, these average values do not differ by more than $10-20 \%$ from the rest of the coupon area, which meant that the strain field was relatively constant over the specimen with just a minor moment gradient being produced for the column bending test. Therefore, the constant coupon curvature assumption during CBT employed can be considered acceptable for most engineering purposes.

Generally, the bending stiffness, $D_{l 1}$ values measured, and the predicted ones with micromechanical and CLT analyses for all the laminates tested at a 0 deg orientation had a maximum difference of $30 \%$ (but in general under $10 \%$ ) for the IM and HM unidirectional laminates and $10 \%$ for the woven and LAM1 laminates evaluated. The $D_{22}$ (or $D_{11}$ at $90 \mathrm{deg}$ ) values had a maximum difference of $40 \%$ and $10 \%$. Finally, the maximum difference in $D_{11}$ values at 45 deg were $50 \%$ and $15 \%$. Possible reasons for the disparities (particularly for off-axis orientations) were; fiber alignment errors and thin-ply material quality for the thin-ply unidirectional coupons fabricated, errors in the micromechanical model used for the woven lamina that was not adapted to unique geometric features of spread-tow fabrics, and matrix shear modulus reductions at larger strains for off-axis laminates subjected to large shear strains during bending. A future micromechanical model of the spread-tow PW lamina built with the parameters taken from the micrograph analysis will be used to formulate a more accurate woven ply model. Improved correlation between model predictions and tests data was achieved when the matrix shear modulus was largely reduced in the computational model. Such response effect is particularly relevant for the final deployable composite boom application at hand, as the constitutive woven-ply materials will be subjected to large shear strains over the stowage phase that will cause matrix relaxation/creep, affecting the stiffness, and properties like bistability ${ }^{19}$, of these thin-shell booms.

In general, the maximum difference in predicted principal surface strains at the calculated average maximum curvatures, and the measured average tensile and compression strains at the moment of failure were $20-35 \%$ for all the materials and laminates evaluated.

Overall, the CBT is an adequate large deformation bending test method for capturing and evaluating the nonlinear bending behavior of thin-ply HSC materials throughout their large strain operational regime. Future tests will continue to evaluate the bending test method presented and extend the database of thin-ply materials and laminates characterized by the CBT method.

\section{Acknowledgements}

This work was financially supported by the NASA Game Changing Development Program (GCDP) Deployable Composite Booms project ${ }^{29}$, as well as Opterus R\&D independent research and development funds. The authors thank past and present NASA LaRC interns, Charles White, Matthew Lee, Kelsey Herrmann, Sarvenaz Ghaffari, Luis Rodriguez and Victoria Gonzalez for their contributions to this research effort. Assistance from NASA LaRC fabrication technicians Jacob Tury, Kevin McLain, Arthur White, and Steve Whitt, for specimen manufacturing and cutting is also gratefully acknowledged.

\section{References}

${ }^{1}$ Wisnom, M. R., Atkinson, J. W., "Constrained buckling Tests Show Increasing Compressive Strains to Failure with Increasing Strain Gradients", Composites Part A:Applied Science and Manufacturing, Vol. 28, No. 11, 1997, pp. 959-964.

${ }^{2}$ Montagnier, O., "Compression Characterization of High-Modulus Carbon Fibers", Journal of Composite Materials, Vol. 39, No. 1, 2005, pp. 35-49.

${ }^{3}$ Yee, J. C. H., Pellegrino, S., "Folding of woven composite structures", Composites Part A:Applied Science and Manufacturing, Vol. 36, 2005, pp. 273-278.

${ }^{4}$ Yee, J. C. H., Soykasap, O., Pellegrino, S. "Carbon Fibre Reinforced Plastic Tape Springs", $45^{\text {th }}$ AIAA Structures, Structural Dynamics, and Materials Conference, Palm Springs, California, 19-22 April 2004. 
${ }^{5}$ Yee, J. C. H., Pellegrino, S., "Biaxial Bending Failure Locus for Woven-Thin-Ply Carbon Fiber Reinforced Plastic Structures", $46^{\text {th }}$ AIAA Structures, Structural Dynamics, and Materials Conference, Austin, Texas, 18-21 April 2005.

${ }^{6}$ Yee, J. C. H., Pellegrino, S., “Composite tube hinges”, Journal of Aerospace Engineering, Vol. 18, No. 4, 2005 , pp. $224-231$.

${ }^{7}$ Murphey, T. W., Sanford, G. E., Grigoriev, M. M., "Nonlinear elastic constitutive modeling of large strains in carbon fiber composites flexures", 16 $6^{\text {th }}$ International Conference on Composite Materials (ICCS-16), Porto, Portugal, $28-30$ June 2011.

${ }^{8}$ Sanford, G., Biskner, A., Murphey, T. W., "Large Strain Behavior of Thin Unidirectional Composite Flexures", $51^{s t}$ AIAA Structures, Structural Dynamics, and Materials Conference, Orlando, Florida, 12-15 April 2010.

${ }^{9}$ Murphey, T. W., Peterson, M. E., Grigoriev, M. M., "Large Strain Four-Point Bending of Thin Unidirectional Composites", AIAA Journal of Spacecraft and Rockets, Vol. 52, No. 3., 2015, pp. 882-895.

${ }^{10}$ Curtis, P. T., "CRAG Test methods for measurement of engineering properties of fibre reinforced plastics", Composite Research Advisory Group (CRAG), 1988.

${ }^{11}$ ASTM D790M-03, "Standard Test Method for Flexural Properties of Unreinforced and Reinforced Plastics and Electrical Insulating Materials", ASTM International, 2003.

${ }^{12}$ Lopez Jimenez, F., "Mechanics of Thin Carbon Fiber Composites with a Silicone Matrix", PhD Dissertation, California Institute of Technology, Pasadena, California, 2011.

${ }^{13}$ Sanford, G. E., Ardelean, E. V., Murphey, T. W., and Grigoriev, M. M., "High strain test method for thin composite laminates," 16 $6^{\text {th }}$ International Conference on Composite Materials (ICCS-16), Porto, Portugal, 28-30 June 2011.

${ }^{14}$ Peterson, M. E., Murphey, T. W., "High Strain Flexural Characterization of Thin CFRP Unidirectional Composite Lamina", $31^{\text {st }}$ American Society for Composites Technical Conference, Williamsburg, Virginia, 19-22 September 2016.

${ }^{15}$ Peterson, M. E., Murphey, T. W., "Large Deformation Bending of Thin Composite Tape Spring Laminates", $54^{\text {th }}$ AIAA Structures, Structural Dynamics, and Materials Conference, Boston, Massachusetts, 8-11 April 2013.

${ }^{16}$ Fernandez, J. M., et al., "NASA's Advanced Solar Sail Propulsion System for Low-Cost Deep Space Exploration and Science Missions that Use High Performance Rollable Composite Booms", 4th International Symposium on Solar Sailing, Kyoto, Japan, 17-20 Jan. 2017.

${ }^{17}$ Fernandez, J. M., et al., "An Advanced Composites-Based Solar Sail System for Interplanetary Small Satellite Missions", $5^{\text {th }}$ AIAA Spacecraft Structures Conference, AIAA Scitech 2018 Forum, Kissimmee, FL, 8-12 Jan. 2018

${ }^{18}$ Fernandez, J. M. "Advanced Deployable Shell-Based Composite Booms for Small Satellite Applications including Solar Sails", 4th International Symposium on Solar Sailing, Kyoto, Japan, 17-20 Jan. 2017.

${ }^{19}$ Lee, A. J., Fernandez, J. M., "Mechanics of Bistable Two-shelled Composite Booms", 5 ${ }^{\text {th }}$ AIAA Spacecraft Structures Conference, AIAA Scitech 2018 Forum, Kissimmee, FL, 8-12 Jan. 2018.

${ }^{20}$ Medina, K. A., Rose, T. J., Murphey, T. W., "Initial Investigation of Time Dependency on Failure Curvatures of FlexLam High Strain Composites," 32 nd American Society for Composites Technical Conference, West Lafayette, IN, 23-25 Oct. 2017.

${ }^{21}$ Tsai, S. W., Sihn, S., Kim, R. Y., "Thin Ply Composites", 46 ${ }^{\text {th }}$ AIAA Structures, Structural Dynamics and Materials Conference, Austin, Texas, 18-21 April 2005.

${ }^{22}$ Correlated Solutions, URL: http://www.correlatedsolutions.com/vic-3d/

${ }^{23}$ Correlated Solutions, URL: http://www.gom.com/metrology-systems/aramis

${ }^{24}$ Rock West Composites, URL: http://www.rockwestcomposites.com/downloads/MR60H-24K (02-2008).pdf

${ }^{25}$ Rock West Composites, URL: https://www.rockwestcomposites.com/downloads/HS40-12K (07-2008).pdf

${ }^{26}$ ASTM D3039/D3039M-14, "Standard Test Method for Tensile Properties of Polymer Matrix Composite Materials", ASTM International, 2014.

${ }^{27}$ Toho Tenax, URL: http://www.tohotenax-us.com//products/CF_Property.pdf

${ }^{28}$ Patz Materials and Technologies, URL: http://patzmandt.com/services/

${ }^{29}$ NASA Space Technology Mission Directorate, Game Changing Development Program, URL: http://gameon.nasa.gov/projects/deployable-composite-booms-dcb 